\title{
Regulation of pathophysiological and tissue regenerative functions of MSCs mediated via the WNT signaling pathway (Review)
}

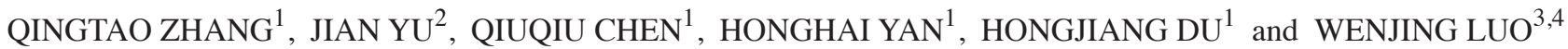 \\ ${ }^{1}$ Department of Stomatology, The Second Affiliated Hospital of Zhejiang Chinese Medical University, Hangzhou, Zhejiang \\ 310085; ${ }^{2}$ Department of Stomatology, Zhejiang Hospital, Hangzhou, Zhejiang 310030, P.R. China; \\ ${ }^{3}$ Department of General Dentistry, Boston University Henry M. Goldman School of Dental Medicine, Boston, MA 02118; \\ ${ }^{4}$ Department of Biomedical Sciences, Texas A\&M University College of Dentistry, Dallas, TX 75246, USA
}

Received August 11, 2020; Accepted June 22, 2021

DOI: $10.3892 / \mathrm{mmr} .2021 .12287$

\begin{abstract}
Tissues have remarkable natural capabilities to regenerate for the purpose of physiological turnover and repair of damage. Adult mesenchymal stem cells (MSCs) are well known for their unique self-renewal ability, pluripotency, homing potential, paracrine effects and immunomodulation. Advanced research of the unique properties of MSCs have opened up new horizons for tissue regenerative therapies. However, certain drawbacks of the application of MSCs, such as the low survival rate of transplanted MSCs, unsatisfactory efficiency and even failure to regenerate under an unbalanced microenvironment, are concerning with regards to their wider therapeutic applications. The activity of stem cells is mainly regulated by the anatomical niche; where they are placed during their clinical and therapeutic applications. Crosstalk between various niche signals maintains MSCs in homeostasis, in which the WNT signaling pathway plays vital roles. Several external or internal stimuli have been reported to interrupt the normal bioactivity of stem cells. The irreversible tissue loss that occurs during infection at the site of tissue grafting suggests an inhibitory effect mediated by microbial infections within MSC niches. In addition, MSC-seeded tissue engineering success is difficult in various tissues, when sites of injury are under the effects of a severe infection despite the immunomodulatory properties of MSCs. In the present review, the current understanding of the way in which WNT signaling regulates MSC activity modification under physiological and pathological conditions was summarized. An effort was also made to illustrate parts of the underlying mechanism, including the inflammatory factors and their interactions with the regulatory WNT signaling pathway, aiming to promote the clinical translation of MSC-based therapy.
\end{abstract}

Correspondence to: Dr Wenjing Luo, Department of General Dentistry, Boston University Henry M. Goldman School of Dental Medicine, 635 Albany Street, Boston, MA 02118, USA

E-mail:mnluo@bu.edu

Key words: pathophysiology, tissue regeneration, regulation, mesenchymal stem cell, WNT pathway

\section{Contents}

1. Introduction

2. WNT signaling pathway

3. Regulatory WNT signaling in MSCs under physiological conditions

4. Regulatory WNT signaling in MSCs under infectious conditions

5. Conclusions and outlook

\section{Introduction}

Mesenchymal stem cells (MSCs) originate in the embryonic mesoderm and can be isolated from several mesenchymal tissues in adults, including the bone marrow (1), adipose tissue (2), craniofacial sutures (3), mouse incisor cervical loop (4), periodontal ligament (5), synovial membrane (6), menstrual fluid (7), dental pulp (8) and umbilical cord blood (9). The definition of classical MSCs was established by the International Society of Cellular Therapy based on in vitro studies in 2006 (10). Briefly, three criteria must be satisfied: i) Typical MSCs must adhere to the plastic plate under standard tissue culture conditions; ii) MSCs must express specific cell surface markers, such as cluster of differentiation (CD)73, CD90 and CD105, and lack certain hematopoietic stem cell markers, including the lipopolysaccharide receptor CD14, CD34 and the leukocyte common antigen CD45; and iii) these cells must have the capacity to be induced to differentiate into adipocytes, osteoblasts and chondrocytes $(10,11)$. Recently, due to MSCs' high self-renewal ability, multi-lineage differentiation potential and immunomodulatory capacity, studies have been devoted to improving the clinical applications of MSCs in tissue regeneration, with or without the aid of a bioengineering scaffold. Several studies have reported the positive therapeutic effects of MSCs $(12,13)$; however, certain questions and challenges arise during the application of MSC therapy, such as the risk for MSC transformation, tumor formation, potential adverse inflammatory effects and thrombosis associated with intravenous infusion of MSCs (14). A previous study reported that the majority of engrafted MSCs died within a few days, making it very difficult to replace the lost tissues, but some of 
the cells were incorporated into tissues following long-term observation (15). To date, the safety of MSC treatment has been proven, but the efficacy and consequent interactions within the host microenvironment remain controversial to a certain degree (16).

Recently, the majority of studies have attributed the failure of stem cell therapy to the imbalances in the MSC niche (12-14). Over 40 years ago, a specialized regulatory bone-marrow (BM) microenvironmental niche was proposed, where stem cells reside, receive appropriate support for maintaining self-renewal and multi-lineage differentiation capacity, and are protected from environmental stress (16). Crosstalk between various niche signals maintains the stem cells in a dynamic balance (17-19). The niche components, including perivascular nerve, endothelial cells and special megakaryocytes, secrete various bioactive proteins, such as mitochondrial inner membrane protein (also known as Sonic hedgehog) (4), WNT, stem cell factors (20), chemokines (C-X-C motif) ligand (CXCL)12 (21) and transforming growth factor- $\beta$ (TGF- $\beta$ ) (22), to participate in MSC maintenance, quiescence, activation and lineage commitment activity. When niche components are ablated, stem cells fail to respond to tissue regeneration cues (23), underscoring the significance of the niche in dictating stem cell behavior (22-24). The activation of signaling pathways is usually switched on, with these pathways mediating stem cell status. Several signaling pathways participate in stem cell activity, including the Notch, Hedgehog $(\mathrm{Hh})$ and bone morphogenetic protein (BMP) signaling pathways. Of note, these signaling pathways exhibit crosstalk with each other, and this determines the activity of cells (25). The Hh signaling pathway is associated with the risk of developing several diseases. The biological and pathogenic importance of Hh signaling emphasizes the need to control its action tightly, both physiologically and therapeutically (26). Notch signaling contains both canonical and noncanonical pathways, is involved in the proliferation, differentiation and survival of multiple types of tissues, and can increase the survival and self-renewal of hematopoietic progenitors in the hematopoietic system (27). The BMP signaling pathway is a well studied pathway, includes the family members BMP2 and 4 , and is associated with the TGF- $\beta$ family. The TGF family plays important roles in embryonic development and in the maintenance of tissue homeostasis (28).

During homeostasis, the concerted action of local positive and negative regulatory niche signals helps maintain adult MSCs in dynamic balance. However, if one certain stimulus is out of control, stem cells cannot maintain their normal function. To cite an example, under periodontal tissue infection (periodontitis), the regeneration of periodontium is hard to achieve (29), which indicates that severe infection may inhibit adult stem cells. Currently, various studies have attempted to explain the way in which the MSCs modify immune responses to improve tissue regeneration ability, with less research focusing on the way in which infectious niche environments influence the activities of adult MSCs. To date, several in vivo and in vitro preliminary studies have shown that the downregulation of MSC bioactivity by infection is mainly mediated by the inhibition of the WNT pathway (30). The role of WNT signaling in the control of MSC biology has been well documented (19,30). Transcriptomic and proteomic approaches, such as ELISA and western blotting, have revealed the enrichment of both canonical and noncanonical WNT pathway components in MSCs (31). The activation of the WNT pathway plays a critical role in cell fate decisions, particularly for MSC proliferation, self-renewal and differentiation. Furthermore, WNT signaling modulation in MSCs has been widely investigated to fully exploit the regenerative properties of MSCs in different fields, such as bone, lung and heart biology $(32,33)$. Our previous study also demonstrated that a decreased expression level of the WNT pathway during periodontitis and overactivation may rescue periodontal tissue loss. In the present review, the WNT pathway and the recent discoveries regarding its role in adult MSCs were summarized. Additionally, the means by which inflammatory signaling can alter MSCs by modifying WNT signaling was explored.

\section{WNT signaling pathway}

The WNT protein family was first identified in 1976 when genetic screens in Drosophila melanogaster had unveiled a set of genes that were essential for the development of the embryo. One of those genes had actually been identified as a weak mutant allele leading to the loss of wing tissue, hence the name 'wingless' (34). For the next few decades, studies consistently found that the WNT signaling cascade is important for embryonic development and tissue homeostasis in adulthood through the regulation of various cellular activities, including proliferation, survival, apoptosis, angiogenesis and cell polarity $(35,36)$. The WNT ligands are a group of secreted glycoproteins that activate their cell surface receptors to induce specific intracellular signaling cascades that control gene expression. Classically, it has been reported that the noncanonical WNT ligands, such as WNT5a and WNT11, and the canonical ligands, such as WNT1, 3a and 8 mediate the $\beta$-catenin signaling pathway (37). WNT5a, the classical noncanonical ligand, has been shown to activate the canonical $\beta$-catenin pathway in the presence of frizzled (FZD)5 (38) or FZD4 and LDL receptor-related protein 5 (LRP5) (39). Based on the extensive study of WNT signaling, two classical pathways, the canonical and noncanonical pathways, have been well established, which are based on the difference of downstream responsive elements to WNT proteins (40). The canonical pathway is mediated by $\beta$-catenin, playing a critical role in governing MSC activity (41). To date, three noncanonical signaling pathways have been characterized: i) The planar cell polarity (PCP) pathway (WNT/PCP pathway) involving Ras-related C3 botulinum toxin substrate 1 (Rac1) and Ras homolog family member A; ii) the WNT/calcium pathway involving protein kinase $\mathrm{C}(\mathrm{PKC})$ and c-Jun $\mathrm{N}$-terminal kinases (JNK); and iii) the WNT5a/FZD2 pathway regulating tumor metastasis via proto-oncogene tyrosine-protein kinase Fyn (FYN) (42). The WNT signaling system is complicated by the presence of different subtypes of LRPs, WNTs, FZDs and regulatory inhibitors, the interaction between canonical and noncanonical pathways, as well as crosstalk with other signaling pathways (43).

Canonical WNT signaling. The $\beta$-catenin-dependent canonical WNT pathway appears to be the most conserved pathway 
in both vertebrates and invertebrates and plays a dual role in adherent junctions and transcriptional regulation (37-39). The receptors in the WNT signaling pathway include single-pass transmembrane co-receptor LRP5/6 and seven transmembrane signaling receptors, FZD (44). The key element is the destruction complex consisting of the scaffold protein Axis inhibitor (AXIN), adenomatous polyposis coli (APC) and casein kinase 1 (CK1). Without WNT ligands, the destruction complex in the cytoplasm is activated to phosphorylate downstream $\beta$-catenin. APC binds $\beta$-catenin and CK1 and primes the protein for the subsequent phosphorylation mediated by recruited glycogen synthase kinase 3 (GSK3) at threonine and serine residues. The phosphorylated $\beta$-catenin is then degenerated by E3 ubiquitin ligase and transferred to proteasomes (Fig. 1A). When the WNT ligands are bonded, dishevelled (DVL) protein is recruited by FZD, and the phosphorylated DVL then phosphorylates and inhibits GSK3. $\beta$-catenin is thus protected from GSK3-dependent phosphorylation. Subsequently, non-phosphorylated $\beta$-catenin is translocated into the nucleus, where it displaces the co-repressor groucho from the transcriptional factor groucho/T cell factor/lymphoid-enhancing factor (TCF/LEF) complex, thereby triggering the transcription of WNT target genes, which mediate MSC bioactivity (Fig. 1B) (45-47).

Noncanonical WNT signaling. To date, two distinct noncanonical WNT signaling pathways have been identified, with different impacts on cell activities. Similar to canonical WNT signaling, DVL is recruited and activated, and the subsequent cascade is meditated by the DVL-associated activator of morphogenesis 1 or DVL-associated small signaling G-protein Rac1. One of these pathways is the WNT-PCP pathway, which is initiated following binding of WNT to FZD together with a transmembrane co-receptor, followed by the activation of the small G-protein Rho by either orphan receptor tyrosine kinase-like receptor 2 (ROR2) or receptor tyrosine kinase through a guanine exchange factor (GEF), followed by the activation of Rho-associated protein kinase (48), an important regulator of the cytoskeleton. As the alternative pathway, Rac1 activates transcription factors through cJNK activation, which is involved in cytoskeleton modification, as well as targets the expression of genes regulating cell survival, movement and polarity (Fig. 2A) $(49,50)$.

Another signaling pathway is the WNT-calcium pathway, which reduces cell adhesion (Fig. 2B). Phosphorylated DVL, following the binding of WNT ligands to FZD, leads to phospholipase $\mathrm{C}$ activation and the subsequent formation of inositol-1,4,5-triphosphate (IP3) and diacylglycerol (DAG) from the cell membrane component, phosphatidylinositol-4,5-bisphosphate (PIP2). IP3 binds to its receptor in the endoplasmic reticulum (ER) membrane, resulting in the release of intracellular calcium $(47,49,50)$. Calcium movement in the cytoplasm then activates calcium-/calmodulin-dependent protein kinase II (CAMKII), which causes nuclear translocation of activated T cells (NFAT) family of transcription factors through the phosphorylation of MAPKs (51), while DAG activates PKC and MAPKs, which all target NFAT inside the nucleus to govern cell movement and adhesion. In addition, the noncanonical WNT-calcium pathway has been reported to inhibit the canonical $\mathrm{WNT} / \beta$-catenin pathway,
Canonical Wnt signaling pathway

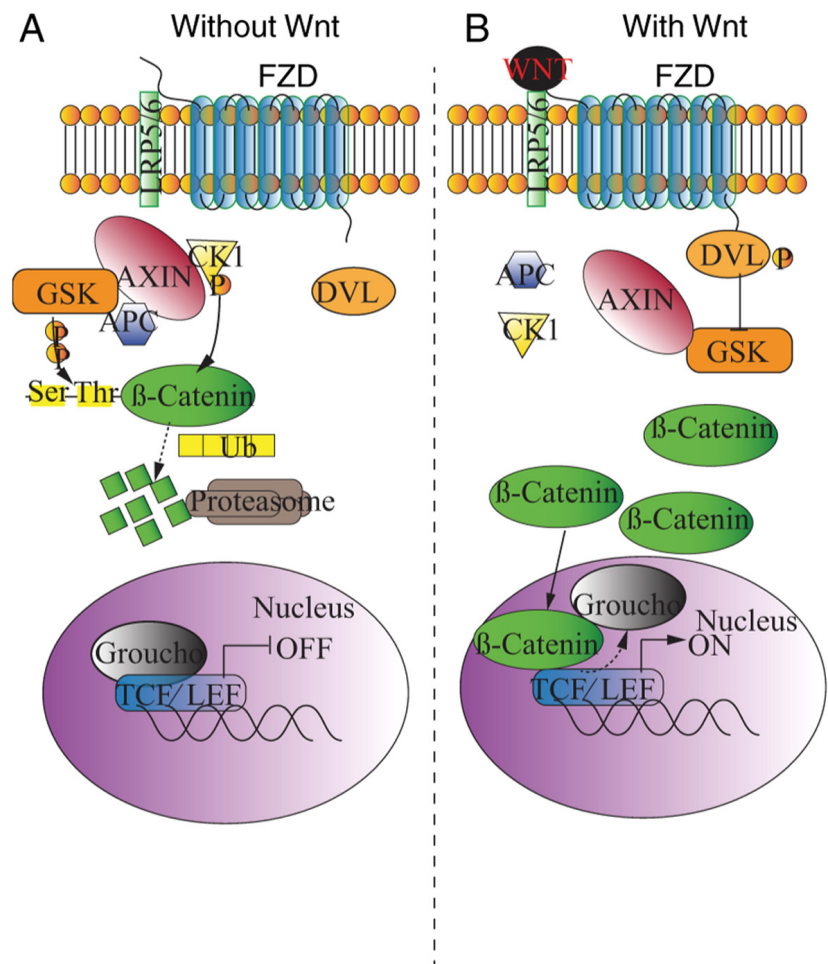

Figure 1. Overview of the canonical WNT pathway. (A) In the canonical pathway without WNT ligands, the destruction complex phosphorylates $\beta$-catenin, which is later ubiquitinated and targeted for degradation in proteasomes. The absence of $\beta$-catenin represses WNT downstream genes. (B) In the canonical pathway with WNT ligand-receptor binding, the recruited DVL blocks GSK, and the destruction complex disassembles to stabilize $\beta$-catenin. The nuclear translocation elicits target gene expression.

since CAMKII can trigger TGF- $\beta$ activated kinase 1 (TAK1) phosphorylation, which in-turn enhances the activity of Nemo-like kinase (NLK), leading to LEF1- $\beta$-catenin/DNA dissociation (Fig. 2B) (52). Recently, another special noncanonical pathway leading to epithelial-mesenchymal transition in cancer cells was discovered (53). Upon WNT5a ligand binding, FZD2 exclusively recruits and phosphorylates DVL. The pathway is achieved through the activation of STAT3 by FYN. STAT3 is translocated to the nucleus and triggers cell migration-related target gene expression, epithelial-mesenchymal transition and tumor cell invasion responsible for tumor metastasis (Fig. 2C) (53).

\section{Regulatory WNT signaling in MSCs under physiological conditions}

Canonical WNT signaling is known to be a critical stem cell niche-regulating pathway in several tissues, such as bone marrow and craniofacial sutures $(3,54)$. WNT signaling has been shown to enhance the effect of osteogenic differentiation of bone marrow BMSC through the canonical WNT pathway. Impaired osteogenic differentiation of zinc metallopeptidase STE24 ${ }^{-/}$BM-MSCs can be partly attributed to decreased calcium expression, which leads to the inhibition of the canonical WNT pathway (54). Gli1+ cells have been proven to localize MSCs throughout the craniofacial sutures, including sagittal, frontal-premaxilla, palatal, coronal and lambdoid 


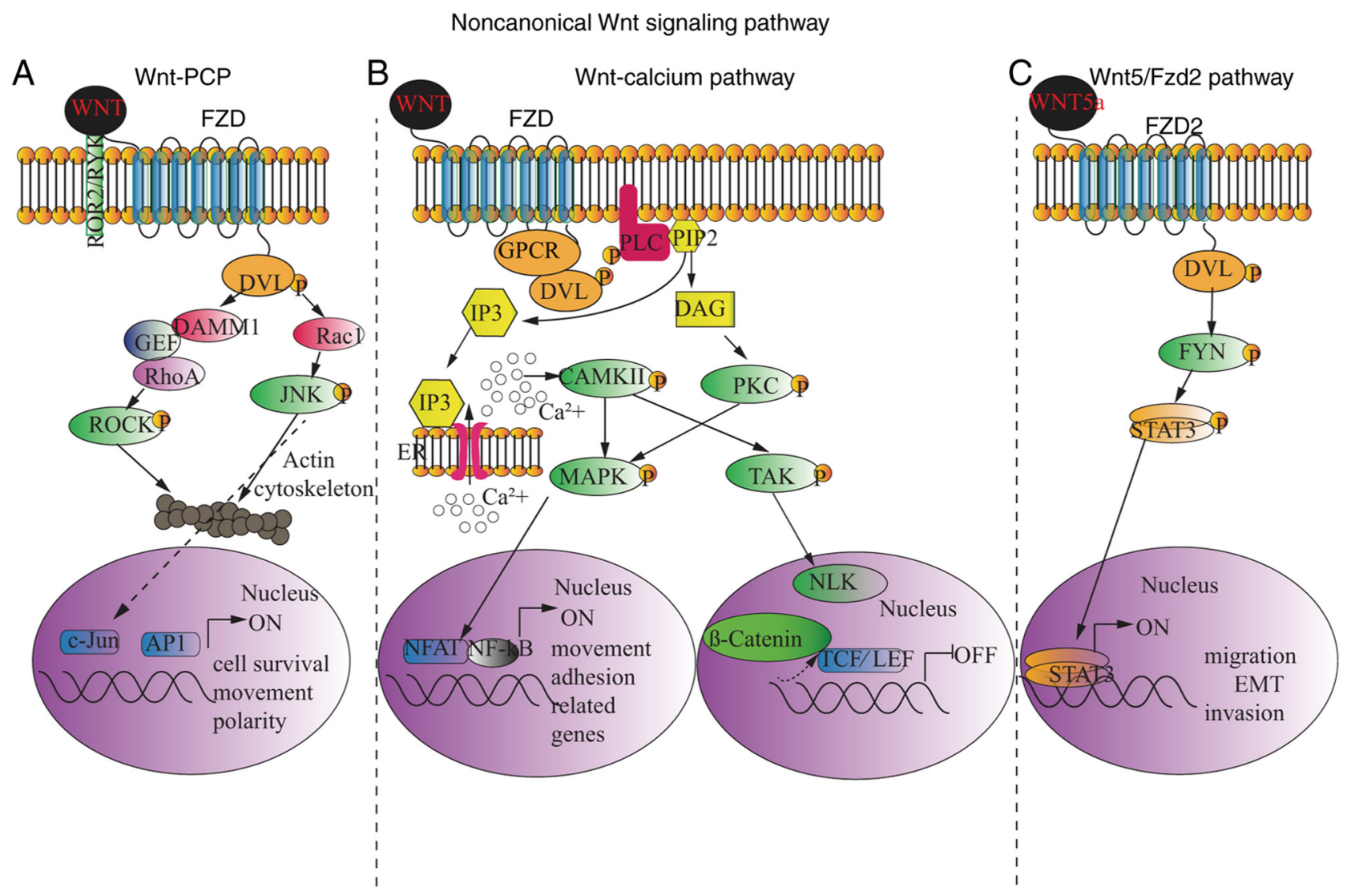

Figure 2. Overview of the noncanonical WNT pathway. (A) Depiction of the noncanonical WNT-PCP pathway. Under DVL and coreceptor ROR2/RYK binding, two Rho family GTPases, RhoA and Rac1, stimulate ROCK and JNK activity, respectively. Both kinases regulate the cytoskeleton directly, and JNK triggers the expression of target genes regulating cell survival, movement and polarity. (B) Schematic representation of the WNT-Ca ${ }^{2+}$ pathway. WNT ligand-FZD binding mediates DVL activation with G protein-coupled receptor. DVL activates PLC to decompose PIP2 into IP3 and DAG. IP3 leads to intracellular $\mathrm{Ca}^{2+}$ release via ER, which in turn phosphorylates CAMKII. CAMKII activates NFAT to regulate cell movement and adhesion-related genes via MAPK, while it inhibits WNT/ $\beta$-catenin signaling through TAK-NLK-mediated LEF1- $\beta$-catenin dissociation from DNA. DAG activates NFAT downstream genes through PKC. (C) Schematic of the WNT5a/FZD2 pathway involved in tumor metastasis-related gene expression via FYN-activated STAT3.

sutures (3). Another study supporting these findings also mentioned that suture MSCs express AXIN2 and are characteristic of long-term self-renewal and clonal expansion during calvarial development and homeostatic maintenance (55). Recently, an exogenous WNT3a protein delivered through liposomes was found to accelerate craniofacial tissue healing $(47,56)$, providing potential therapeutic strategies to promote MSC-based tissue regeneration through the high expression of the WNT signaling pathway (57).

Numerous studies have underscored the importance of WNT signaling as a critical mediator of the homeostasis of MSCs, which are powerful stem cell factors that control the stemness, self-renewal and proliferation of multiple adult stem cell populations (58). Furthermore, the WNT signaling pathway has different impacts on MSCs tri-lineage differentiation (26).

WNT and MSC adipogenic differentiation. Overall, the WNT signaling pathway inhibits MSC adipogenic differentiation. It has been demonstrated that the expression levels of WNT antagonists sFRP4 and dickkopf WNT signaling pathway inhibitor 1 (Dkk1) were higher in adipogenically differentiated than in undifferentiated MSCs (59). Moreover, a short $48 \mathrm{~h}$ treatment of human MSCs with secreted frizzled-related protein (sFRP)1 and sFRP4 was reported to upregulate adiponectin secretion, thereby promoting adipogenesis $(60,47)$. A few clinical trials explored the association between WNT activity, and obesity and diabetes. One of these trials concluded that sFRP4 levels were positively correlated with impaired glucose and triglyceride metabolism (61). Certain studies have used sFRP4 as a predictor of type II diabetes mellitus $(62,63)$. Conversely, a previous study showed that the GSK-3 $\beta$ inhibitor 6-bromo-indirubin-3 $\alpha$-oxime could inhibit MSC adipogenesis, as a result of enhanced WNT signaling (64). Collectively, this evidence showed the inhibitory regulation of WNT on the differentiation of MSCs into adipocytes, suggesting that WNT activators can be used for the treatment of obesity, although this remains under extensive investigation.

WNT and MSC chondrogenic differentiation. There are a number of controversies regarding the function of the WNT pathway in MSC chondrogenesis, which may be a result of the complicated interactions within the WNT signaling network. It was previously shown that an enhanced chondrogenic activity on sFRP1-deficient mice highlighted the positive effect of WNT signaling on MSC chondrogenic differentiation (65). In addition, the activation of noncanonical WNT following WNT5a ligand binding was also found to induce the chondrogenesis of MSCs derived from the chicken wing bud (66). Similarly, an in vitro study showed that WNT3a overexpression was associated with the chondrogenic differentiation of 
C3H10T1/2 murine mesenchymal cells (67). The increase in pre-cartilage condensation in an ex vivo MSC culture in the presence of WNT5a protein further confirmed a promoting effect of WNT signaling on MSC chondrogenesis (66). The underlying mechanism indicates that WNT5a activates the noncanonical WNT pathway and blocks the canonical pathway. However, a different study reported a reduced expression of chondrogenic-specific markers, such as collagen II, SRY-box transcription factor (Sox)9 and aggrecan following continuous treatment with WNT1 protein for 21 days, whereas treatment with the WNT antagonist Dkk1 increased their expression in human adipose-derived MSCs (68). Consistently, a large number of in vitro studies emphasized the importance of suppressed WNT signaling during chondrogenesis. For example, sFRP1 and Dkk1 could accelerate the initial stages of human MSC chondrogenesis, as indicated by the enhanced glycosaminoglycan synthesis, Sox 9 and type II collagen expression (69); these WNT antagonists also exhibited a chondrogenesis-promoting effect in long-term pellet cultures (70). Most of these conclusions were made based on in vitro studies, where the concentration of the WNT pathway regulators and the absence of other interacting pathways could be the reason for the controversial findings. Therefore, these findings warrant additional and more accurate investigations.

WNT and MSC osteogenic differentiation. It has been well-established that the WNT signaling pathway is indispensable for MSC osteogenesis. The canonical WNT signaling pathway activates the differentiation of MSCs into osteoblasts (71). Current research also suggests that the canonical WNT pathway is essential for the contribution of Gli1+ MSCs to alveolar bone development and the blocking of the canonical WNT pathway in catenin conditional knockout mice, which caused severe bone loss (72). The disruption of WNT signaling by a functional mutation or targeted destruction of LRP5 in mice has been shown to promote osteoporosis and a low bone mass phenotype $(73,74)$, whereas its overexpression has been shown to lead to a high bone mass syndrome (75). The WNT/ $\beta$-catenin signaling functions like a switch, favoring MSC osteogenesis at the expense of adipogenesis by modulating the availability of cell-type-specific transcription factors (76). Recently, Src homology region 2 domain-containing phosphatase-1 (SHP1) was found to bind with GSK3 and suppress its kinase activity. In SHP1 partial deficient mice (mev/mev), phosphorylated GSK3 mediated increased $\beta$-catenin degradation, thus these mice developed osteoporosis. Lineage differentiation culture of the bone marrow MSCs extracted from mev/mev mice displayed less osteogenesis and more adipogenesis (77). As expected, WNT antagonism was reported to inhibit osteogenesis. This inhibitory effect was demonstrated by an in vitro study, where sFRP4 inhibited the periodontal MSCs committed to osteogenic progenitor cells (78). Amongst other WNT antagonists, sFRP1 overexpression was found to inhibit in vivo bone formation (79) and deteriorate osteoblast and osteocyte apoptosis (80). Comparatively, the lack of sFRP1 reduced apoptosis, accelerated MSC osteogenic differentiation (81), enhanced trabecular bone formation and improved fracture healing (82-84), confirming the inhibitory effect of WNT antagonists on osteogenesis. In addition, sFRP3 has been shown to repress the noncanonical WNT pathway by binding to WNT5a, which in turn blocks the inhibitory effect of WNT5a on the canonical pathway, hence promoting osteogenesis (78). Collectively, this evidence supported the positive regulation of the canonical WNT pathway on MSC osteogenic differentiation. The extensive crosstalk within the WNT signaling network during osteogenic differentiation should be considered when devising possible new therapeutic approaches for bone-related diseases.

\section{Regulatory WNT signaling in MSCs under infectious conditions}

MSCs' niche homeostasis is influenced by the internal and external microenvironments, including pathogens, DNA damage and metabolic stress. Microbiota, as an external stimulus, plays a regulatory role in MSC health. The absence of MHC class-II and low expression levels of class-I antigens endow MSCs with low immunogenic potential, rendering them more suitable for MSC-based tissue regeneration medicine (84). However, unexpected infection is the cause of failure of tissue repair, suggesting that implanted MSCs may be affected by the recipient immune system (78). During this repair process, coordinated and precise crosstalk between endotoxins of microorganisms, inflammatory cells, cytokines and regulatory signaling cascades with MSCs is critical for the success of tissue regeneration $(85,86)$. The failure in this communication is associated with arrested MSC activity and may further lead to wound healing defects, inflammatory disorders, and even malignant transformation $(87,88)$. Particularly, the regenerative capacities of endogenous or transplanted stem cells are significantly modified by the immune microenvironment at the site of injury (89-92). For example, it has been shown that recipient $\mathrm{T}$ cells negatively regulate autologous MSCs mediating bone formation in the mouse, and that NF- $\mathrm{NB}$, the major transcription factor in both the innate and adaptive immune response, represses bone formation in rats (93). Lung tumor cell-derived exosomes can 'educate' naive MSCs into pro-inflammatory MSCs by activating Toll-like receptor (TLR)2/IL-1/myeloid-differentiation primary-response protein 88 (MyD88) signaling through HSP70 (94). Radiation-induced bowel injury may damage RNA, causing crypt stem cells death via TLR3 signaling (91). Hence, an in-depth understanding of the pattern of how the immune system governs MSC behavior could provide insights into therapeutic avenues for restoring damaged tissues efficiently $(87,90)$.

In addition, previous studies have provided evidence of the association between inflammatory signaling pathways and the WNT pathway, which may underlie the regulation of the immune system on MSCs. The examples include tissue repair by macrophage-activating stem cells via WNT pathway upregulation through the secretion of WNT7b and WNT10a, and progenitor cells through WNT3a (95). Furthermore, certain studies have suggested that under the attack of replicative pathogenic microorganisms, MSCs undergo rapid aging (96-98). The aged stem cells have been reported to exhibit downregulated WNT pathway activity, indicating the inhibitory regulation of stem cell infection via the WNT pathway (99). 
The complex pathophysiological mechanism of tissue injury has been delineated through the continuous efforts of immunological studies $(100,101)$. This complex process involves the recognition of the molecules of typical pathogens', recruited immune cells, secreted inflammatory cytokines and molecular pathway interplay with local tissue cells, including MSCs. First, there are five classes of germline-encoded host-pathogen sensors, which are collectively termed pattern recognition receptors (PRRs) (102-104). These elements can recognize the specific molecules on microorganisms known as pathogen-associated molecular patterns (PAMPs). PRRs include the following: i) TLRs, transmembrane proteins located primarily at the cell surface or in endosomes; ii) nucleotide-binding oligomerization domain-like receptors (NLRs), the intracellular sensors inside the cytoplasm; iii) retinoic acid-inducible gene-I-like receptors, which are intracellularly located and primarily involved in antiviral responses; iv) C-type lectin receptors, carbohydrate-binding transmembrane receptors functioning in the immune response to pathogens and apoptosis; and v) absence in melanoma 2-like receptors, characterized by a pyrin domain and a DNA-binding HIN domain detecting intracellular microbial DNA. Each PRR triggers inflammatory pathways to fight against microorganisms in various ways, amongst which, TLRs and NLRs were key components of the innate immune response (105).

Impact of TLR pathways, on MSCs and the regulatory WNT pathway. TLRs are dominantly expressed on the membranes of leukocytes, including dendritic cells, macrophages, natural killer cells, and T and B lymphocytes. To date, 13 members of the TLR family have been identified, of which TLR1, TLR2, TLR4, TLR5, TLR6 and TLR11 are expressed on the cell surface, and TLR3, TLR7, TLR8 and TLR9 are localized to the endosomal/lysosomal compartments. TLR12 and TLR13 are not found in humans (106). Each of these TLRs binds to and becomes activated by different ligands. For example, lipopolysaccharides (LPSs) exclusively bind to TLR4, but TLR4 can also be activated by multiple other pathogens. TLR3 can be activated by Poly I:C-a mismatched double-stranded RNA in viral infection (107). Lipoteichoic acid (108), the immunostimulant of Gram-positive bacteria, is recognized by TLR2. The inflammatory pathways initiated after this receptor-ligand binding and their downstream responsive adaptors are also different for each TLR. However, overall, all the TLR inflammatory pathways act through two major signaling cascades: A MyD88-dependent pathway inducing pro-inflammatory cytokines, such as TNF- $\alpha$ via NF- $\kappa \mathrm{B}$ and a MyD88 independent pathway that acts through type I interferons (109). The dominant MyD88-dependent pathway originates from the cytoplasmic Toll/IL-1 receptor (TIR) domain. Upon stimulation with extracellular PAMPs, MyD88 attaches to TLRs through the TIR domain and recruits IL-1 receptor-associated kinase-4 (IRAK-4) to TLRs. Following phosphorylation, the IRAK1/2/4 complex is connected to TNF receptor-associated factor 6 (TRAF6), which then activates TAK1, leading to the activation of the I $\kappa \mathrm{B}$ kinase (IKK) complex. The downstream I $\kappa \mathrm{B}$ kinase phosphorylates the inhibitory $\mathrm{I} \kappa \mathrm{B} \alpha$ protein $(73,110)$. This phosphorylation dissociates $\mathrm{I} \kappa \mathrm{B} \alpha$ from $\mathrm{NF}-\kappa \mathrm{B}$, with the free $N F-\kappa B$ then able to translocate into the nucleus to activate the target genes responsible for pro-inflammatory cytokine transcription, such as pro-IL-1 $\beta$ and pro-IL-18. The enhancement of the transcription of the same target genes can also be mediated by activated mitogen-activated protein kinase kinases to phosphorylate MAPKs including JNK, ERK and p38 (111). The activation of MyD88-independent pathways occurs via TIR-domain-containing adapter-inducing interferon- $\beta$ and TRAF3 in case of MyD88 deficiency. It induces the recruitment of IKKع/TBK1, phosphorylation of interferon regulatory factor 3 (IRF3) and expression of interferon- $\beta$. Thus far, most TLR-related inflammation is mediated by the MyD88-dependent pathway, whereas PolyI: C-TLR3 antiviral innate immunity has been found to be independent of MyD88 (Fig. 3A) (112).

TLRs and IL-1R ligands are usually found to be highly expressed in sites of tissue injury and wound repair $(113,114)$, and it has been shown that they could influence the repair process $(115,116)$. Thus, it is reasonable to conclude that TLR inflammatory pathways have an impact on the behavior of MSCs. It has been well established by several in vitro studies that MSCs express a number of TLRs. Thus far, consistent results have demonstrated the expression of TLR1-6 in adipose- and bone marrow-MSCs in both humans and mice and at both the mRNA and protein levels, whereas inconsistent results have been reported on the expression of TLR7-10 (84,117). TLR/Myd88/IL receptor 1 (ILR1) signaling inhibits BM-MSC colony formation, proliferation, migration and osteoblastic differentiation after being activated by IL-1 $\beta$. It is worth mentioning that BM-MSCs are more vulnerable to the inhibitory effects of TLR/Myd88/ILR1 signaling than osteoblasts (30). Pevsner-Fischer et al (118) found that TLR2 activation reduced mouse BM-MSC differentiation into the three mesodermal lineages. Of note, BM-MSCs collected from MyD88-deficient mice were found to effectively differentiate into adipocytes, but not osteocytes or chondrocytes, even without the additional stimulation with TLR ligands. Similarly, another two studies reported that the activation of the TLR4 or 2 pathway in the proinflammatory environment negatively regulated human adipose MSC (hAD-MSC) differentiation to adipocytes $(119,120)$. Collectively, these findings indicated that the effects of the TLR pathway on MSC lineage commitment potentials varies depending on different culture conditions, tissue origins and species (118). However, most of the available evidence on the association between the infectious TLR pathway and MSCs are based on in vitro studies. In vitro cultures do not completely replicate in vivo MSC behavior, as it is unable to incorporate the complicated interactions between the numerous signaling pathways employed by the various cell types. A good example of this difference between in vivo and in vitro studies is the fact that in BM-MSC-based calvaria regeneration, delivering Myd88-- MSCs induced a significantly higher regeneration capacity compared with wild-type (wt) MSCs, whereas the in vitro culture of $\mathrm{Myd} 88^{-/-}$and wt MSCs resulted in equal differentiation and proliferation ability (30).

It is well known that the oral cavity is subjected to daily assaults from the external microbiota, which inevitably causes periodontitis. In periodontitis, LPS can cause periodontal tissue degeneration in a dose-time-dependent manner (121), which indicates the failure of periodontal MSCs to support physiological turnover. The modulation of WNT/ $\beta$-catenin signaling helps attenuate periapical bone lesions (122). An in vitro study 
demonstrated that LPS activated p38-MAPK and inhibited the canonical WNT/ $\beta$-catenin signaling pathway with an increase in the levels of p38, c-myc, cyclin D1 mRNA and phosphorylated GSK-3 $\beta$ (123). During the process of wound repair, prostaglandin E2 (PGE2) released from neighboring apoptotic cells can activate the WNT/ $\beta$-catenin pathway in MSCs via WNT3. LPS was also reported to enhance WNT5a expression through the TLR4/MyD88/phosphatidylinositol 3-OH kinase/Akt/NF- $\mathrm{B} / \mathrm{MAPK}$ pathway, based on in vitro studies of human dental pulp stem $(124,125)$ and osteoblast (126) cells. However, there are a number of controversies on the influence of Pg-LPS on dental MSC function and the pathways involved. It has been shown that Pg-LPS modified periodontal ligament stem cell lineage commitment during the inhibition of osteogenesis and stimulation of fibrosis via ERK1/2 signaling (127). Moreover, Pg-LPS inhibited the osteogenic differentiation of BM-MSCs (127), whereas LPS upregulated gingival MSC proliferation without attenuating their regenerative capacity, and this positive effect was mediated by the NF- $\kappa \mathrm{B}$ but not the WNT/ $\beta$-catenin pathway (127).

The digestive system is another non-sterile environment that is exposed to a wide array of microorganisms, with infectious bowel diseases being relatively common as a result (128). Under infectious conditions, intestinal MSCs can differentiate into inflammatory cells and secrete inflammatory cytokines, such as IL-1b, IL-8 and TNF- $\alpha$ (129). When treating intestinal MSCs with LPS, flow cytometry analysis showed that the LPS-induced MSC cell cycle progression was arrested at the G1 phase, and that cell pyroptosis was enhanced. Studies have shown that LPS inhibits WNT signaling through the activation of GSK $3 \beta$, causing a marked inhibition in enterocyte proliferation, both in vitro and in vivo (130). This particular phenomenon links the LPS/TLR4 pathway to the regulation of intestinal MSC lineage commitment by WNT.

Of note, Liu et al (131) found that although Salmonella effector Protein AvrA presents in certain intestinal microorganisms of Salmonella and E. coli, it specifically upregulates the expression of WNT genes and phosphorylation of $\beta$-catenin, thus leading to a marked increase in crypt proliferation with a significant reduction in Lgr5+ intestinal stem cells in their model $(131,132)$.

The above findings suggested an influence of the TLR inflammatory pathway on the regulatory WNT pathway in MSCs, with the molecular mechanism of this interaction partially revealed. TLRs can modulate WNT activity at different points with various effects. First, TLRs can modulate the activity of WNT degradation of $\beta$-catenin by binding to the LRP5/6 FZD receptor complex, thus promoting the function of the $\beta$-catenin destruction complex, with subsequent blocking of the WNT target gene expression. However, this interactive mechanism helps explain the fact that transiting WNT3a could counteract the inhibitory effect of Pg-LPS. TAK1 phosphorylation in TLR signaling attributes to NLK activation, which is negatively correlated with the canonical WNT pathway downstream TCF/LEF transcription (133). By contrast, TLRs can activate AKT through PI3K and IKK, consequently inhibiting GSK $3 \beta$, enhancing $\beta$-catenin expression and upregulating TCF/LEF transcription. TLR4/Myd88/leucine-rich repeat (LRR) binding FLII interacting protein 2 has also been revealed as an activator of WNT by interacting with DVL to activate catenin/LEF/TCF-dependent transcriptional activity (Fig. 3A and B) (134,135).

NLR pathway and MSCs. In addition to TLRs, vertebrates have developed several alternative strategies to sense pathogens in the cytosol $(136,137)$. NLRs are the intracellular receptors playing key roles in innate immune system regulation by sensing PAMPs that enter the cell via phagocytosis or through pores, and cell stress-related damage-associated molecular patterns (106). NLRs are composed of 3 major domains: The central NOD nucleotide-binding domain (NACHT) domain is common to all NLRs; most NLRs also have similar C-terminal LRR and variable N-terminal interaction domains (114). Each domain has a specific function; LRR recognizes ligands, the central NACHT domain mediates adenosine triphosphate (ATP)-dependent self-oligomerization, and $\mathrm{N}$-terminal domain triggers homotypic protein interaction amongst the caspase recruitment domain (CARD; from the NLRC subfamily), pyrin domain (PYD; from the NLRP subfamily), acidic transactivating domain (from the NLRA subfamily) or baculovirus inhibitor repeats (BIRs; from the NLRB subfamily) $(138,139)$.

NLRs mediate inflammasome formation and downstream caspase-1 activation, resulting in programmed cell death under infectious conditions, a phenomenon known as pyroptosis. The manifestation of pyroptosis can be induced by pyknosis, chromatin condensation, DNA breaks, plasma membrane permeabilization and cellular swelling (140). Following TLR-related 'priming' and 'activating', NLR ligand uptake triggers inflammasome assembly, and maturation of IL-1 $\beta$ and IL-18. NLRs directly bind to apoptosis-associated speck-like protein (ASC) through PYD, and ASC binds to pro-caspase-1 through its CARD domain (141). NLR signaling-driven pyroptosis can be mediated by the canonical and noncanonical inflammasome pathway. In the canonical inflammasome pathway, the combination of NLRs/ASC activates pro inflammasome 1 and organizes the functional caspase-1 into a multiprotein oligomer complex. The activated caspase- 1 induces IL- $1 \beta$ and IL-18 secretion from pro-IL-1 $\beta$ and pro-IL-18. As a consequence, inflammatory immune cells are attracted, and pro-inflammatory cytokines (such as TNF- $\alpha$ and IL-6), chemokines (such as IL-8, CXCL8 and monocyte chemoattractant protein 1) and adhesion molecules are released. In addition, the $\mathrm{K}^{+}$selective hemichannel on the inflammatory cell surface is opened upon ATP binding, with the subsequent $\mathrm{K}^{+}$efflux inducing pore formation on the cell membrane via pannexin-1, and extracellular pathogen influx further deteriorating pyroptosis. The noncanonical pathway works in synergy with the canonical pathway. In the non-canonical pathway, caspase-11 activation directly enhances IL-1 $\beta$ and IL-18 release and promotes the canonical caspase-1 pathway (142). Subsequently, the release of IL-1 $\beta$ and IL-18, and proteolytic cleavage of Gasdermin-D into Gasdermin-N domain by caspase-4, 5 and 11 either directly activate caspase-1 or indirectly activate the canonical inflammasome/NLR pathway to induce pyroptosis $(142,143)$.

A previous in vitro study on human umbilical cord blood-derived MSCs (hUCB-MSCs) and hAD-MSCs reported that hUCB-MSCs expressed bioactive NOD1 and 2 genes. The administration of NLR agonists has led to IL-8 


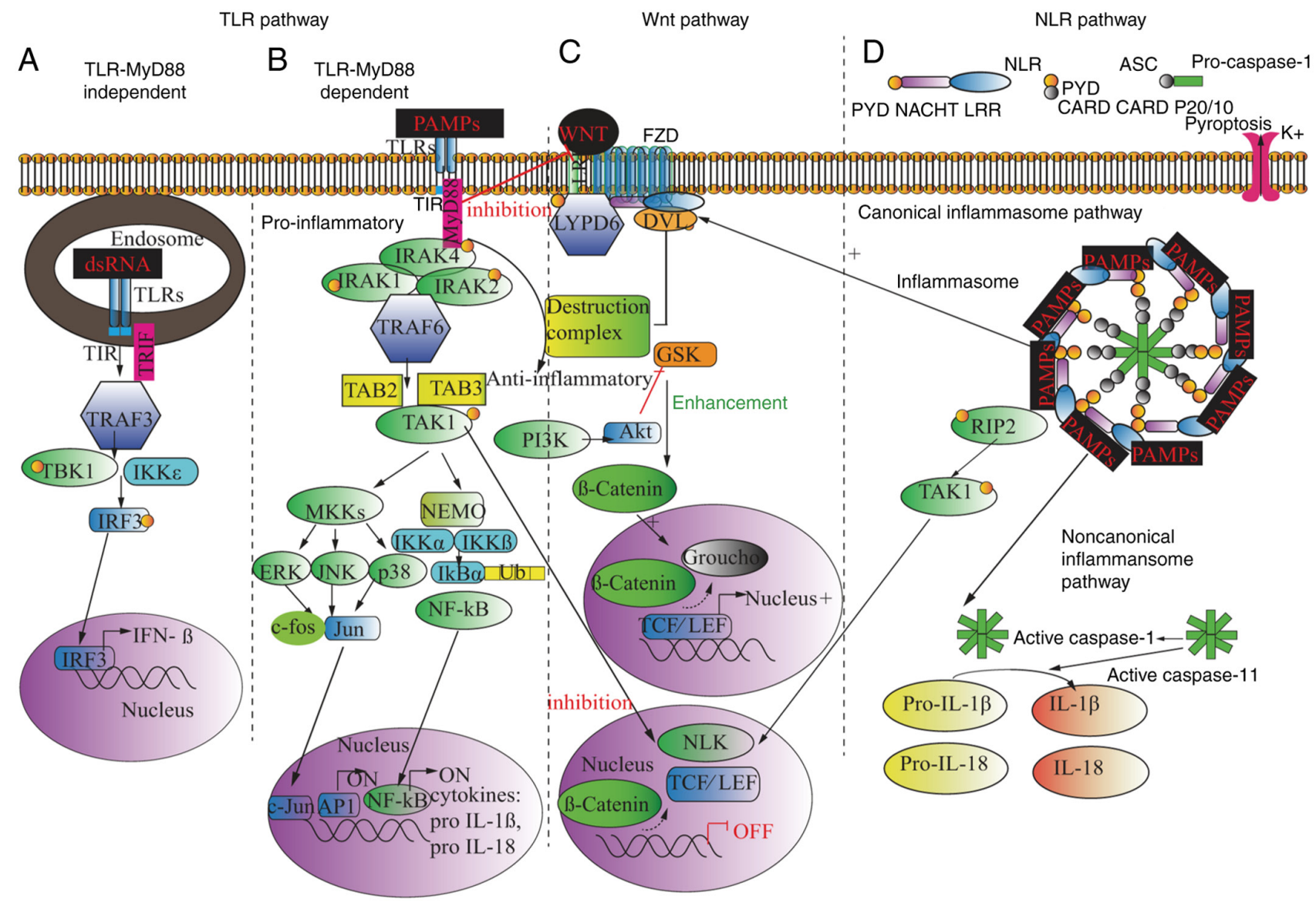

Figure 3. TLR pathway, NLR pathway and their effects on the WNT/B-catenin signaling. (A) Depiction of TLR-MyD88 independent pathway with terminal IFN-1 $\beta$ secretion. Intracellular PAMP-dsRNA in endosomes is recognized by TLR3, and IKKe/TBK1 are recruited to phosphorylate IRF3 via TRIF and TRAF3. IRF3 is translocated to the nucleus to induce IFN-1 $\beta$ expression. (B) Overview of TLR-MyD88-dependent pathway inducing pro-inflammatory cytokines, such as pro-IL-1 $\beta$ and pro-IL-18. Upon extracellular binding of PAMPs, TLRs recruit MyD88 to cytoplasmic TIR. MyD88 associates with IRAKs, in which IRAK4 phosphorylates IRAK1 and 2 and promotes their association with TRAF6, and this in-turn recruits and activates TAK1. TAK1 then acti-

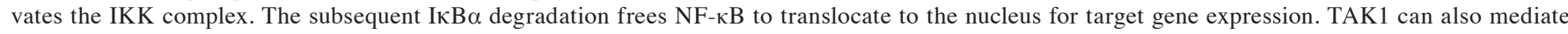
pro-inflammatory cytokine expression through MKKs/MAPK cascades. (C) Diagram indicating the positive and negative influence of inflammatory pathways on WNT signaling. TLRs/MyD88 inhibits the binding of WNT ligands to the LRP5/6 Fz receptor complex. Phosphorylated TAK1 activates NLK, which separates $\beta$-catenin/TCF-LEF from DNA. In addition, activated NLR could also inhibit WNT through the same TAK1/NLK pathway following RIP2 attachment and phosphorylation. Positively, the combination of MyD88 triggers the anti-inflammatory pathway achieved through PI3K/Akt activation. Akt enhances $\beta$-catenin level and expression of WNT target genes. Alternatively, activated NLRs interact with WNT receptors via LYPD6. (D) NLR pathway including the canonical/noncanonical inflammasome pathway. Following extracellular PAMP recognition by NLRs, ASC directly attaches to NLRs via the PYD domain and pro-caspase-1 via CARD. Inflammasomes self-assemble, leading to the cleavage of caspase-1. The activated caspase- 1 catalyzes pro-IL-1 $\beta$ and pro-IL-18 into functional IL-1 $\beta$ and IL-18. $\mathrm{K}^{+}$ion channels on the inflammatory cell surface are activated by active caspase-1, which results in pore formation in the cell membrane. In the noncanonical pathway, caspase-11 activation can directly enhance IL-1 $\beta$ and IL-18 release and promote the caspase-1 pathway.

production. Activated NLR pathways enhance hUCB-MSC osteogenesis and chondrogenesis, and inhibit adipogenic differentiation, but with no marked effects on MSC proliferation (144). Controversially, another in vitro BM-MSC culture study demonstrated increased MSC adipogenesis and decreased MSC osteogenesis in the presence of the NLRP3 inflammasome, which may be explained by the fact that these stem cells originated from different tissues. The inhibition of caspase-1 activation offered a novel therapeutic target for ageing-related chronic inflammatory diseases, such as osteoporosis (145). Despite the contrasting results, the aforementioned findings suggest that NLR pathways serve a pivotal role in MSC regulation. The literature discussing the impact of NLR pathways on WNT signaling is very limited, and the available evidence suggests that receptor-interacting protein kinase 2 (RIP2) containing the CARD domain binds to NLR-inflammasome and undergoes phosphorylation. The
NLR pathway can negatively regulate the WNT pathway via the TAK/NLK cascade (146-148). Of note, certain studies have reported that NOD2 can function as a positive regulator of WNT signaling. The activation is achieved in a noncanonical, RIP2-TGF $\beta$-TAK1-independent manner (149-151). As an alternative approach, NOD2 was found to stimulate and mediate the WNT pathway through Ly6/PLAUR domain-containing protein 6 , which synergizes the ligand-receptor combination in the WNT pathway (Fig. 3C and D) (149).

Proinflammatory cytokines and MSCs. Various in vivo and in vitro studies have shown that the inflammatory cytokines secreted during tissue infections may affect stem cell activities. In most cases, proinflammatory cytokines have been shown to repress various aspects of MSC behavior. The endogenous pro-inflammatory cytokine IL-1 $\beta$ activates IL-1R/MyD88 signaling, thus impairing MSC proliferation, migration and 
differentiation by inhibiting the AKT/GSK-3 $\beta / \beta$-catenin pathway (30). Loss of function studies have shown that IL-1 $\beta$-initiated IL-1R/Myd88 signaling impairs stem cell proliferation, migration and differentiation (152). IL-1 $\beta$ and IL-18 have also been identified to directly kill stem cells in vitro (153). Similarly, IL-1 $\beta$ was found to inhibit BMSC osteogenesis by activating Foxhead box D3 protein-mediated miR-496 expression (154). Interferon- $\alpha$ (IFN- $\alpha$ ) acts as a central mediator of adaptive immunity, and has been shown to stimulate bone loss during inflammation (155). The combination of IFN- $\gamma$ and TNF- $\alpha$ can accelerate MSC apoptosis through the internalization of Fas cell surface death receptor, with a reduction in the expression of anti-apoptotic factors, such as NF- $\mathrm{KB}, \mathrm{X}$-linked inhibitor of apoptosis protein and FLICE-like inhibitory protein, whereas TNF- $\alpha$ alone may induce MSC apoptosis in a dose-dependent manner. The administration of recombinant TNF- $\alpha$ has been shown to inhibit MSC adipogenesis and osteoblastogenesis, thus promoting bone resorption $(156,157)$. IFN- $\gamma$ and TNF- $\alpha$ secreted from lymphocytes may synergistically block MSC-based bone regeneration (93). Following treatment of bone marrow MSCs with IFN- $\gamma$ alone, or a combination of IFN- $\gamma$ and TNF- $\alpha$ in vitro, IFN- $\gamma$ was found to block osteogenic differentiation at the same time as upregulating SMAD family member 6 and inhibiting Runt-related transcription factor 2 (158). Both IFN- $\gamma$ and TNF- $\alpha$ were shown to promote the phosphorylation of $\mathrm{p} 38 \mathrm{MAPK}$, which was associated with the downregulation of cyclooxygenase-2/PGE2, and this in turn may gradually reduce the immunomodulatory ability of MSCs (159).

ROS by-products and their impact on MSCs. The activation of TLR and NLR pathways may trigger the production of a common by-product, antimicrobial ROS (160). ROS are short-lived oxygen-containing molecules existing in the form of free redials, including superoxide anion $\left(\mathrm{O}_{2}^{-}\right)$, hydroxyl radical $(\mathrm{OH})$, hydroxyl ion $\left(\mathrm{OH}^{-}\right)$and nitric oxide $(\mathrm{NO})$, as well as non-radical ROS, such as hydrogen peroxide $\left(\mathrm{H}_{2} \mathrm{O}_{2}\right)(161)$. ROS production occurs under different physiological and pathological circumstances aided by active enzymes (162). ROS are ubiquitously found in the extracellular space (163), plasma membrane (164) and intracellular compartments [including mitochondria, where nicotinamide adenine dinucleotide phosphate (NADPH) oxidases are concentrated] (165), peroxisomes, ER (166) and cytosol (NO synthases and lipoxygenases) (167). However, amongst these, mitochondrial complexes I and III, and the corresponding NADPH oxidase isoform NADPH oxidase 4, are the major sources of ROS production that play pivotal roles in MSC regulatory niches (168). Several studies have concluded that local hypoxia is the culprit for the failure of MSC-based tissue regeneration and MSC ageing $(169,170)$.

ROS influence MSC survival in a concentration-dependent manner. An appropriate level of ROS is necessary and advantageous to maintain cellular proliferation and survival; however, excessive ROS may cause cellular damage and dysfunction after initiating chemical reactions involving RNA, DNA, proteins and lipids $(161,171,172)$. Eto et al (173) demonstrated that AD-MSCs were extremely sensitive to oxygen concentration, with only cells implanted $<300 \mathrm{~mm}$ from an oxygen source surviving and the rest undergoing apoptosis. However, excess ROS has been confirmed to activate MAPK pathways and apoptotic proteins, and suppress antiapoptotic pathways $(173,174)$. Consistently, antioxidants stimulate MSC proliferation (175).

ROS involvement in the regulation of MSC differentiation may stem from the difference in ROS levels within the differentiated and undifferentiated MSCs. During homeostasis, undifferentiated MSCs are predominantly supported by glycolytic energy with higher levels of glycolytic enzymes and increased lactate production. By contrast, MSC-differentiated osteoblasts rely more on oxidative mitochondrial metabolism (176). Therefore, MSCs exhibit relatively low levels of ROS, but low antioxidant activity may suggest that they are more sensitive to oxidative stress (177-179). In fact, the impact of ROS on MSC lineage differentiation significantly varies depending on the dosage. The in vivo and in vitro studies collectively suggested that excessive ROS could suppress osteogenesis but induce adipogenic differentiation (180). Highly well-defined levels of ROS may activate MSC differentiation into chondrocytes (144), adipocytes (181), osteocytes (46) and neurons (182) through the enhanced activity of regulatory signaling pathways, including the WNT pathway. A previous in vitro study verified that the exogenous addition of $\mathrm{H}_{2} \mathrm{O}_{2}$ inhibits TCF-mediated transcription and that $\beta$-catenin overexpression and use of antioxidants could rescue that inhibition. In addition, ROS concomitantly increases with ageing, with the aged MSCs reported to exhibit a reduced expression of WNT target genes, such as AXIN2 and TNF receptor superfamily member 11b, in 31-month-old mice compared with 4-month-old mice, thus diminishing osteogenesis (183). An in vivo study revealed that irradiation injury could cause intestinal tissue regeneration via the activation of WNT signaling, which was achieved through the ROS/hypoxia-inducible factor/WNT2b signaling axis (132). One explanation of this mechanism could be that superoxide-generating NADPH oxidase (Nox) induces ROS production, leading to the inactivation of nucleoredoxin (NRX) in the $\beta$-catenin destruction complex to activate the WNT/ $\beta$-catenin pathway (184). Conversely, in the MSC niche, the binding of WNT ligand to its receptor complexes may trigger the sequential activation of Src kinase, Rac1-GEF-vav guanine nucleotide exchange factor 2 through Src-dependent tyrosine phosphorylation and Rac1. Activated Rac1 may in turn induce Nox1-derived ROS, which may result in the oxidation of NRX, with the oxidized NRX then detaching from DVL. Subsequently, liberated DVL suppresses the $\beta$-catenin destruction complex, resulting in the stabilization of $\beta$-catenin and the activation of WNT signaling $(184,185)$.

\section{Conclusions and outlook}

MSCs are well known for their multipotency, regenerative ability and immunomodulatory properties. The stem cell niches may play a crucial role in regulating their self-renewal, differentiation and cell fate. Although MSC-based tissue regeneration has led to notable developments over the past decade, no associated clinical standard therapy has been developed, due to the low effectiveness of MSCs. Insights into the crosstalk between regulatory factors within MSC niches and MSCs are important for both normal tissue homeostasis and disease conditions, such as tissue infection. WNT signaling is broadly involved in the regulation of adult MSC fate in various tissues. The canonical 
WNT/ $\beta$ catenin pathway may help with the maintenance of MSC stemness and proliferation ability. However, WNT signaling has been shown several times to inhibit adipogenic activity and enhance osteogenic differentiation. Inflammation is the protective response of the host body against various harmful stimuli. However, the host defense may not be able to deal with the constant attack by pathogens, which could lead to harmful infection, and this may break down or upset the balance of MSC niches. MSCs are regulated by inflammatory factors. Currently, most studies are focusing on the investigation of MSC modulatory effects on the immune system and their application in the treatment of a variety of immunoproliferative diseases and improvement of tissue injury repair efficiency. Less attention has been paid to establishing how the immune response to infection affects the functional restorative capacity of MSCs. In the present review, the current knowledge on the behavioral changes of MSCs under the influence of various immune response-mediated pathways and immune regulatory reactions, such as the TLR pathway, NLR pathway, pro-inflammatory cytokines, ROS by-products and the modifications mediating WNT signaling, were summarized.

Following the recognition of PAMPs and PRRs, the active TLR pathway inhibits MSC proliferation and tissue-specific differentiation by interrupting WNT signaling at different points, including the LRP5/6 FZD receptor and GSK $3 \beta$-destruction complexes or by directly terminating TCF/LEF transcription. NLR pathways mediate inflammasome formation and the resulting pyroptosis. NLRs modify MSC lineage distribution profiles that vary greatly amongst different tissue origins. Numerous proinflammatory cytokines have been found to inhibit the normal functions of MSCs and exert undesirable tissue regenerative effects. ROS, as one of the common by-products of immune infection, may function as a positive regulator of the WNT pathway and MSC activity at an appropriate level; however, extremely high levels of ROS may deplete MSC survival and damage TCF transcription, which are crucial for MSC differentiation. Future prospective research is required to unravel the regulation of MSCs in relation to the pathophysiology of immune defense response to infections and their terminal fate, as MSC-based tissue regeneration may have a therapeutic effect.

\section{Acknowledgements}

Not applicable.

\section{Funding}

No funding was received.

\section{Availability of data and materials}

The datasets used and/or analyzed during the study are available from the corresponding author on reasonable request.

\section{Authors' contributions}

WL, QZ and HY designed and supervised the study. JY, QZ, QC and HD analyzed and interpreted the data. QZ and JY wrote the manuscript. All authors read and approved the final manuscript. Data authentication is not applicable.

\section{Ethics approval and consent to participate}

Not applicable.

\section{Patient consent for publication}

Not applicable.

\section{Competing interests}

The authors declare that they have no competing interests.

\section{References}

1. Bianco P, Riminucci M, Gronthos S and Robey PG: Bone marrow stromal stem cells: Nature, biology, and potential applications. Stem Cells 19: 180-192, 2001.

2. Zuk PA, Zhu M, Mizuno H, Huang J, Futrell JW, Katz AJ, Benhaim P, Lorenz HP and Hedrick MH: Multilineage cells from human adipose tissue: Implications for cell-based therapies. Tissue Eng 7: 211-228, 2001.

3. Zhao H, Feng J, Ho TV, Grimes W, Urata M and Chai Y: The suture provides a niche for mesenchymal stem cells of craniofacial bones. Nat Cell Biol 17: 386-396, 2015.

4. Zhao H, Feng J, Seidel K, Shi S, Klein O, Sharpe P and Chai Y: Secretion of shh by a neurovascular bundle niche supports mesenchymal stem cell homeostasis in the adult mouse incisor. Cell Stem Cell 14: 160-173, 2014.

5. Seo BM, Miura M, Gronthos S, Bartold PM, Batouli S, Brahim J, Young M, Robey PG, Wang CY and Shi S: Investigation of multipotent postnatal stem cells from human periodontal ligament. Lancet 364: 149-155, 2004.

6. Harvanová D, Tóthová T, Sarišský M, Amrichová J and Rosocha J: Isolation and characterization of synovial mesenchymal stem cells. Folia Biol (Praha) 57: 119-124, 2011.

7. Patel AN,Park E, Kuzman M, Benetti F, Silva FJ and Allickson JG: Multipotent menstrual blood stromal stem cells: Isolation, characterization, and differentiation. Cell Transplant 17: 303-311, 2008.

8. Agha-Hosseini F, Jahani MA, Jahani M, Mirzaii-Dizgah I and Ali-Moghaddam K: In vitro isolation of stem cells derived from human dental pulp. Clin Transplant 24: E23-E28, 2010.

9. Weiss ML, Medicetty S, Bledsoe AR, Rachakatla RS, Choi M, Merchav S, Luo Y, Rao MS, Velagaleti G and Troyer D: Human umbilical cord matrix stem cells: Preliminary characterization and effect of transplantation in a rodent model of Parkinson's disease. Stem Cells 24: 781-792, 2006.

10. Divya MS, Roshin GE, DivyaTS, Rasheed VA, SanthoshkumarTR, Elizabeth KE, James J and Pillai RM: Umbilical cord blood-derived mesenchymal stem cells consist of a unique population of progenitors co-expressing mesenchymal stem cell and neuronal markers capable of instantaneous neuronal differentiation. Stem Cell Res Ther 3: 57, 2012.

11. Pittenger MF, Mackay AM, Beck SC, Jaiswal RK, Douglas R, Mosca JD, Moorman MA, Simonetti DW, Craig S and Marshak DR: Multilineage potential of adult human mesenchymal stem cells. Science 284: 143-147, 1999.

12. Tavakoli S, Ghaderi Jafarbeigloo HR, Shariati A, Jahangiryan A, Jadidi F, Jadidi Kouhbanani MA, Hassanzadeh A, Zamani M, Javidi K and Naimi A: Mesenchymal stromal cells; a new horizon in regenerative medicine. J Cell Physiol 235: 9185-9210, 2020.

13. Hoogduijn MJ and Lombardo E: Mesenchymal stromal cells anno 2019: dawn of the therapeutic Era? concise review. Stem Cells Transl Med 8: 1126-1134, 2019.

14. Najar M, Bouhtit F, Melki R, Afif H, Hamal A, Fahmi H, Merimi M and Lagneaux L: Mesenchymal stromal cell-based therapy: New perspectives and challenges. J Clin Med 8: 626, 2019.

15. Chen C and Hou J: Mesenchymal stem cell-based therapy in kidney transplantation. Stem Cell Res Ther 7: 16, 2016. 
16. Schofield R: The relationship between the spleen colony-forming cell and the haemopoietic stem cell. Blood Cells 4: 7-25, 1978.

17. Martino MM, Briquez PS, Güc E, Tortelli F, Kilarski WW, Metzger S, Rice JJ, Kuhn GA, Müller R, Swartz MA and Hubbell JA: Growth factors engineered for super-affinity to the extracellular matrix enhance tissue healing. Science 343 885-888, 2014.

18. Adam RC and Fuchs E: The yin and yang of chromatin dynamics in stem cell fate selection. Trends Genet 32: 89-100, 2016.

19. Kim JH, Liu X, Wang J, Chen X, Zhang H, Kim SH, Cui J, Li R, Zhang W, Kong Y, et al: Wnt signaling in bone formation and its therapeutic potential for bone diseases. Ther Adv Musculoskelet Dis 5: 13-31, 2013.

20. Ding L and Morrison SJ: Haematopoietic stem cells and early lymphoid progenitors occupy distinct bone marrow niches. Nature 495: 231-235, 2013.

21. Bruns I, Lucas D, Pinho S, Ahmed J, Lambert MP, Kunisaki Y, Scheiermann C, Schiff L, Poncz M, Bergman A and Frenette PS: Megakaryocytes regulate hematopoietic stem cell quiescence through CXCL4 secretion. Nat Med 20: 1315-1320, 2014.

22. Zhao M, Perry JM, Marshall H, Venkatraman A, Qian P, He XC, Ahamed $\mathrm{J}$ and $\mathrm{Li} \mathrm{L}$ : Megakaryocytes maintain homeostatic quiescence and promote post-injury regeneration of hematopoietic stem cells. Nat Med 20: 1321-1326, 2014

23. Rompolas P, Deschene ER, Zito G, Gonzalez DG, Saotome I, Haberman AM and Greco V: Live imaging of stem cell and progeny behaviour in physiological hair-follicle regeneration. Nature 487: 496-499, 2012.

24. Spradling A, Drummond-Barbosa D and Kai T: Stem cells find their niche. Nature 414: 98-104, 2001

25. Bitgood MJ and McMahon AP: Hedgehog and Bmp genes are coexpressed at many diverse sites of cell-cell interaction in the mouse embryo. Dev Biol 172: 126-138, 1995.

26. Petrova R and Joyner AL: Roles for Hedgehog signaling in adult organ homeostasis and repair. Development 141: 3445-3457, 2014.

27. Ohishi K, Varnum-Finney B, Flowers D, Anasetti C, Myerson D and Bernstein ID: Monocytes express high amounts of Notch and undergo cytokine specific apoptosis following interaction with the Notch ligand, Delta-1. Blood 95: 2847-2854, 2000.

28. Verrecchia $F$ and Mauviel A: Transforming growth factor- $\beta$ and fibrosis. World J Gastroenterol 13: 3056-3062, 2007.

29. Han J, Menicanin D, Gronthos S and Bartold PM: Stem cells, tissue engineering and periodontal regeneration. Aust Dent J 59 (Suppl 1): S117-S130, 2014.

30. Martino MM, Maruyama K, Kuhn GA, Satoh T, Takeuchi O, Müller R and Akira S: Inhibition of IL-1R1/MyD88 signalling promotes mesenchymal stem cell-driven tissue regeneration. Nat Commun 7: 11051, 2016.

31. Kuljanin M, Bell GI, Sherman SE, Lajoie GA and Hess DA: Proteomic characterisation reveals active Wnt-signalling by human multipotent stromal cells as a key regulator of beta cel survival and proliferation. Diabetologia 60: 1987-1998, 2017.

32. Volleman TNE, Schol J, Morita K, Sakai D and Watanabe M: Wnt3a and wnt5a as potential chondrogenic stimulators for nucleus pulposus cell induction: A comprehensive review. Neurospine 17: 19-35, 2020.

33. Sato A, Yamamoto H, Sakane H, Koyama H and Kikuchi A: Wnt5a regulates distinct signalling pathways by binding to Frizzled2. EMBO J 29: 41-54, 2010

34. Sharma RP and Chopra VL: Effect of the Wingless (wg1) mutation on wing and haltere development in Drosophila melanogaster. Dev Biol 48: 461-465, 1976.

35. Cadigan KM and Nusse R: WNT signaling: A common theme in animal development. Genes Dev 11: 3286-3305, 1997.

36. Wodarz A and Nusse R: Mechanisms of WNT signaling in development. Annu Rev Cell Dev Biol 14: 59-88, 1998.

37. Rao TP and Kühl M: An updated overview on Wnt signaling pathways: A prelude for more. Circ Res 106: 1798-1806, 2010.

38. Heethoff M, Helfen L and Norton RA: Description of Neoliodes dominicus n.sp. (Acari, Oribatida) from Dominican amber, aided by synchrotron X-ray microtomography. J Paleontol 83: 153-159, 2009.

39. Nelson WJ and Nusse R: Convergence of WNT, beta-catenin, and cadherin pathways. Science 303: 1483-1487, 2004.

40. Komiya $\mathrm{Y}$ and Habas R: Wnt signal transduction pathways. Organogenesis 4: 68-75, 2008.

41. He X, Semenov M, Tamai K and Zeng X: LDL receptor-related proteins 5 and 6 in Wnt/beta-catenin signaling: Arrows point the way. Development 131: 1663-1677, 2004.
42. Matsui T, Raya A, Kawakami Y, Callol-Massot C, Capdevila J, Rodríguez-Esteban C and Izpisúa Belmonte JC: Noncanonical Wnt signaling regulates midline convergence of organ primordia during zebrafish development. Genes Dev 19: 164-175, 2005.

43. Kaur P, Jin HJ, Lusk JB and Tolwinski NS: Modeling the role of wnt signaling in human and drosophila stem cells. Genes (Basel) 9: 101, 2018

44. Nusse R: Wnt signaling in disease and in development. Cell Res 15: 28-32, 2005

45. Baron R and Kneissel M: WNT signaling in bone homeostasis and disease: From human mutations to treatments. Nat Med 19: 179-192, 2013.

46. Takada I, Kouzmenko AP and Kato S: WNT and PPARgamma signaling in osteoblastogenesis and adipogenesis. Nat Rev Rheumatol 5: 442-447, 2009

47. Visweswaran M, Pohl S, Arfuso F, Newsholme P, Dilley R, Pervaiz S and Dharmarajan A: Multi-lineage differentiation of mesenchymal stem cells-To WNT, or not WNT. Int J Biochem Cell Biol 68: 139-147, 2015.

48. Ko JH, Lee HJ, Jeong HJ, Kim MK, Wee WR, Yoon SO, Choi H, Prockop DJ and Oh JY: Mesenchymal stem/stromal cells precondition lung monocytes/macrophages to produce tolerance against allo- and autoimmunity in the eye. Proc Natl Acad Sci USA 113 $158-163,2016$.

49. Huelsken J and Behrens J: The WNT signalling pathway. J Cell Sci 115: 3977-3978, 2002

50. Komiya Y and Habas R: WNT signal transduction pathways. Organogenesis 4: 68-75, 2008.

51. Murphy LL and Hughes CC: Endothelial cells stimulate T cell NFAT nuclear translocation in the presence of cyclosporin A: Involvement of the WNT/glycogen synthase kinase-3 beta pathway. J Immunol 169: 3717-3725, 2002.

52. Veltri A, Lang C and Lien WH: Concise review: WNT signaling pathways in skin development and epidermal stem cells. Stem Cells 36: 22-35, 2018.

53. Kim KA, Kakitani M, Zhao J, Oshima T, Tang T, Binnerts M, Liu Y, Boyle B, Park E, Emtage P, et al: Mitogenic influence of human R-spondin1 on the intestinal epithelium. Science 309: $1256-1259,2005$

54. Fei D, Zhang Y, Wu J, Zhang H, Liu A, He X, Wang J, Li B, Wang $Q$ and Jin Y: Cav 1.2 regulates osteogenesis of bone marrow-derived mesenchymal stem cells via canonical Wnt pathway in age-related osteoporosis. Aging Cell 18: e12967, 2019.

55. Maruyama T, Jeong J, Sheu TJ and Hsu W: Stem cells of the suture mesenchyme in craniofacial bone development, repair and regeneration. Nat Commun 7: 10526, 2016.

56. Jing H, Liao L, An Y, Su X, Liu S, Shuai Y, Zhang X and Jin Y: Suppression of EZH2 Prevents the Shift of Osteoporotic MSC Fate to adipocyte and enhances bone formation during osteoporosis. Mol Ther 24: 217-229, 2016.

57. Niehrs $\mathrm{C}$ and Acebron SP: Mitotic and mitogenic WNT signalling. EMBO J 31: 2705-2713, 2012.

58. $\mathrm{Li} \mathrm{L}$ and Clevers $\mathrm{H}$ : Coexistence of quiescent and active adult stem cells in mammals. Science 327: 542-545, 2010.

59. Park JR, Jung JW, Lee YS and Kang KS: The roles of WNT antagonists Dkk1 and sFRP4 during adipogenesis of human adipose tissue-derived mesenchymal stem cells. Cell Prolif 41: 859-874, 2008

60. Ehrlund A, Mejhert N, Lorente-Cebrián S, Aström G, Dahlman I, Laurencikiene J and Rydén M: Characterization of the WNT inhibitors secreted frizzled-related proteins (SFRPs) in human adipose tissue. J Clin Endocrinol Metab 98: E503-E508, 2013.

61. Hoffmann MM, Werner C, Böhm M, Laufs U and Winkler K: Association of secreted frizzled-related protein 4 (SFRP4) with type 2 diabetes in patients with stable coronary artery disease. Cardiovasc Diabetol 13: 155, 2014

62. Mahdi T, Hänzelmann S, Salehi A, Muhammed SJ, Reinbothe TM, Tang Y, Axelsson AS, Zhou Y, Jing X, Almgren P, et al: Secreted frizzled-related protein 4 reduces insulin secretion and is overexpressed in type 2 diabetes. Cell Metab 16: 625-633, 2012

63. Eizirik DL and Cnop M: Mining genes in type 2 diabetic islets and finding gold. Cell Metab 16: 555-557, 2012

64. Zaragosi LE, Wdziekonski B, Fontaine C, Villageois P, Peraldi P and Dani C: Effects of GSK3 inhibitors on in vitro expansion and differentiation of human adipose-derived stem cells into adipocytes. BMC Cell Biol 9: 11, 2008.

65. Gaur T, Rich L, Lengner CJ, Hussain S, Trevant B, Ayers D, Stein JL, Bodine PV, Komm BS, Stein GS and Lian JB: Secreted frizzled related protein 1 regulates WNT signaling for BMP2 induced chondrocyte differentiation. J Cell Physiol 208: 87-96, 2006. 
66. Jin EJ, Park JH, Lee SY, Chun JS, Bang OS and Kang SS: WNT-5a is involved in TGF-beta3-stimulated chondrogenic differentiation of chick wing bud mesenchymal cells. Int J Biochem Cell Biol 38: 183-195, 2006

67. Fischer L, Boland G and Tuan RS: WNT signaling during BMP-2 stimulation of mesenchymal chondrogenesis. J Cell Biochem 84 816-831, 2002

68. Luo S, Shi Q, Zha Z, Yao P, Lin H, Liu N, Wu H and Sun S: Inactivation of $\mathrm{WNT} / \beta$-catenin signaling in human adipose-derived stem cells is necessary for chondrogenic differentiation and maintenance. Biomed Pharmacother 67: 819-824, 2013.

69. Im GI and Quan Z: The effects of WNT inhibitors on the chondrogenesis of human mesenchymal stem cells. Tissue Eng Part A 16: 2405-2413, 2010 .

70. Im GI, Lee JM and Kim HJ: WNT inhibitors enhance chondrogenesis of human mesenchymal stem cells in a long-term pellet culture. Biotechnol Lett 33: 1061-1068, 2011.

71. Liu G, Vijayakumar S, Grumolato L, Arroyave R, Qiao H, Akiri G and Aaronson SA: Canonical WNTs function as potent regulators of osteogenesis by human mesenchymal stem cells. J Cell Biol 185: 67-75, 2009.

72. Men Y, Wang Y, Yi Y, Jing D, Luo W, Shen B, Stenberg W, Chai Y, Ge WP, Feng JQ and Zhao H: Gli1 ${ }^{+}$periodontium stem cells are regulated by osteocytes and occlusal force. Dev Cell 54 639-654.e6, 2020

73. Gong Y, Slee RB, Fukai N, Rawadi G, Roman-Roman S, Reginato AM, Wang H, Cundy T, Glorieux FH, Lev D, et al: LDL receptor-related protein 5 (LRP5) affects bone accrual and eye development. Cell 107: 513-523, 2001

74. Kato M, Patel MS, Levasseur R, Lobov I, Chang BH, Glass DA II, Hartmann C, Li L, Hwang TH, Brayton CF, et al: Cbfa1-independent decrease in osteoblast proliferation, osteopenia, and persistent embryonic eye vascularization in mice deficient in Lrp5, a WNT coreceptor. J Cell Biol 157: 303-314, 2002.

75. Boyden LM, Mao J, Belsky J, Mitzner L, Farhi A, Mitnick MA, Wu D, Insogna K and Lifton RP: High bone density due to a mutation in LDL-receptor-related protein 5. N Engl J Med 346: $1513-1521,2002$

76. Bennett CN, Longo KA, Wright WS, Suva LJ, Lane TF, Hankenson KD and MacDougald OA: Regulation of osteoblastogenesis and bone mass by WNT10b. Proc Natl Acad Sci USA 102: 3324-3329, 2005

77. Jiang M, Zheng C, Shou P, Li N, Cao G, Chen Q, Xu C, Du L, Yang Q, Cao J, et al: SHP1 regulates bone mass by directing mesenchymal stem cell differentiation. Cell Rep 16: 769-780, 2016.

78. Yamada A, Iwata T, Yamato M, Okano T and Izumi Y: Diverse functions of secreted frizzled-related proteins in the osteoblastogenesis of human multipotent mesenchymal stromal cells. Biomaterials 34: 3270-3278, 2013.

79. Yao W, Cheng Z, Shahnazari M, Dai W, Johnson ML and Lane NE: Overexpression of secreted frizzled-related protein 1 inhibits bone formation and attenuates parathyroid hormone bone anabolic effects. J Bone Miner Res 25: 190-199, 2010.

80. Nakanishi R, Akiyama H, Kimura H, Otsuki B, Shimizu M, Tsuboyama $\mathrm{T}$ and Nakamura T: Osteoblast-targeted expression of Sfrp4 in mice results in low bone mass. J Bone Miner Res 23: 271-277, 2008

81. Bodine PV, Billiard J, Moran RA, Ponce-de-Leon H, McLarney S, Mangine A, Scrimo MJ, Bhat RA, Stauffer B, Green J, et al: The WNT antagonist secreted frizzled-related protein-1 controls osteoblast and osteocyte apoptosis. J Cell Biochem 96: 1212-1230, 2005

82. Gaur T, Wixted JJ, Hussain S, O'Connell SL, Morgan EF, Ayers DC, Komm BS, Bodine PV, Stein GS and Lian JB: Secreted frizzled related protein 1 is a target to improve fracture healing. J Cell Physiol 220: 174-181, 2009.

83. Trevant B, Gaur T, Hussain S, Symons J, Komm BS, Bodine PV, Stein GS and Lian JB: Expression of secreted frizzled related protein 1, a WNT antagonist, in brain, kidney, and skeleton is dispensable for normal embryonic development. J Cell Physiol 217: 113-126, 2008.

84. Rashedi I, Gómez-Aristizábal A, Wang XH, Viswanathan S and Keating A: TLR3 or TLR4 activation enhances mesenchymal stromal cell-mediated treg induction via notch signaling. Stem Cells 35: 265-275, 2017.

85. Di Meglio P, Perera GK and Nestle FO: The multitasking organ: Recent insights into skin immune function. Immunity 35 : $857-869,2011$
86. Gurtner GC, Werner S, Barrandon Y and Longaker MT: Wound repair and regeneration. Nature 453: 314-321, 2008.

87. Hanahan D and Weinberg RA: Hallmarks of cancer: The next generation. Cell 144: 646-674, 2011

88. Coussens LM and Werb Z: Inflammation and cancer. Nature 420 860-867, 2002.

89. Aurora AB and Olson EN: Immune modulation of stem cells and regeneration. Cell Stem Cell 15: 14-25, 2014.

90. Forbes SJ and Rosenthal N: Preparing the ground for tissue regeneration: From mechanism to therapy. Nat Med 20: 857-869, 2014.

91. Takemura N, Kawasaki T, Kunisawa J, Sato S, Lamichhane A, Kobiyama K, Aoshi T, Ito J,Mizuguchi K, Karuppuchamy T, et al: Blockade of TLR3 protects mice from lethal radiation-induced gastrointestinal syndrome. Nat Commun 5: 3492, 2014.

92. Burzyn D, Kuswanto W, Kolodin D, Shadrach JL, Cerletti M, Jang Y, Sefik E, Tan TG, Wagers AJ and Mathis D: A special population of regulatory $\mathrm{T}$ cells potentiates muscle repair. Cell 155: 1282-1295, 2013

93. Liu Y, Wang L, Kikuiri T, Akiyama K, Chen C, Xu X, Yang R, Chen W, Wang S and Shi S: Mesenchymal stem cell-based tissue regeneration is governed by recipient T lymphocytes via IFN- $\gamma$ and TNF- $\alpha$. Nat Med 17: 1594-1601, 2011.

94. Li X, Wang S, Zhu R, Li H, Han Q and Zhao RC: Lung tumor exosomes induce a pro-inflammatory phenotype in mesenchymal stem cells via NFkB-TLR signaling pathway. J Hematol Oncol 9: 42, 2016

95. Wynn TA and Vannella KM: Macrophages in tissue repair, regeneration, and fibrosis. Immunity 44: 450-462, 2016.

96. Mejia-Ramirez E and Florian MC: Understanding intrinsic hematopoietic stem cell aging. Haematologica 105: 22-37, 2020

97. Oh J, Lee YD and Wagers AJ: Stem cell aging: Mechanisms, regulators and therapeutic opportunities. Nat Med 20: 870-880, 2014.

98. Liu L and Rando TA: Manifestations and mechanisms of stem cell aging. J Cell Biol 193: 257-266, 2011.

99. Keyes BE and Fuchs E: Stem cells: Aging and transcriptional fingerprints. J Cell Biol 217: 79-92, 2018.

100. Janeway CA Jr: Approaching the asymptote? Evolution and revolution in immunology. Cold Spring Harb Symp Quant Biol 54: 1-13, 1989.

101. Kubelkova K and Macela A: Innate immune recognition: An issue more complex than expected. Front Cell Infect Microbiol 9 241, 2019.

102. Unterholzner L, Keating SE, Baran M, Horan KA, Jensen SB Sharma S, Sirois CM, Jin T, Latz E, Xiao TS, et al: IFI16 is an innate immune sensor for intracellular DNA. Nat Immunol 11: 997-1004, 2010.

103. Schroder K and Tschopp J: The inflammasomes. Cell 140: $821-832,2010$

104. Martinon F, Mayor A and Tschopp J: The inflammasomes: Guardians of the body. Annu Rev Immunol 27: 229-265, 2009

105. Davis BK, Wen $\mathrm{H}$ and Ting JP: The inflammasome NLRs in immunity, inflammation, and associated diseases. Annu Rev Immunol 29: 707-735, 2011.

106. Mahla RS, Reddy MC, Prasad DV and Kumar H: Sweeten PAMPs: Role of sugar complexed PAMPs in innate immunity and vaccine biology. Front Immunol 4: 248, 2013.

107. Fortier ME, Kent S, Ashdown H, Poole S, Boksa P and Luheshi GN: The viral mimic, polyinosinic:polycytidylic acid, induces fever in rats via an interleukin-1-dependent mechanism. Am J Physiol Regul Integr Comp Physiol 287: R759-R766, 2004

108. Sultan M, Coyle KM, Vidovic D, Thomas ML, Gujar S and Marcato P: Hide-and-seek: The interplay between cancer stem cells and the immune system. Carcinogenesis 38: 107-118, 2017.

109. Feng G, Zheng K, Cao T, Zhang J, Lian M, Huang D, Wei C, $\mathrm{Gu} \mathrm{Z}$ and Feng X: Repeated stimulation by LPS promotes the senescence of DPSCs via TLR4/MyD88-NF- $\mathrm{BB}-\mathrm{p} 53 / \mathrm{p} 21$ signaling. Cytotechnology 70: 1023-1035, 2018.

110. Kain M: How NF-kappaB is activated: The role of the IkappaB kinase (IKK) complex. Oncogene 18: 6867-6874, 1999.

111. Blasius AL and Beutler B: Intracellular toll-like receptors. Immunity 32: 305-315, 2010

112. Lester SN and Li K: Toll-like receptors in antiviral innate immunity. J Mol Biol 426: 1246-1264, 2014

113. Piccinini AM and Midwood KS: DAMPening inflammation by modulating TLR signalling. Mediators Inflamm 2010: 672395, 2010.

114. Chen GY and Nuñez G: Sterile inflammation: Sensing and reacting to damage. Nat Rev Immunol 10: 826-837, 2010. 
115. Arslan F, Smeets MB, Riem Vis PW, Karper JC, Quax PH, Bongartz LG, Peters JH, Hoefer IE, Doevendans PA, Pasterkamp $\mathrm{G}$ and de Kleijn DP: Lack of fibronectin-EDA promotes survival and prevents adverse remodeling and heart function deterioration after myocardial infarction. Circ Res 108 : 582-592, 2011.

116. Oyama J, Blais C Jr, Liu X, Pu M, Kobzik L, Kelly RA and Bourcier T: Reduced myocardial ischemia-reperfusion injury in toll-like receptor 4-deficient mice. Circulation 109: 784-789, 2004.

117. DelaRosa O and Lombardo E: Modulation of adult mesenchymal stem cells activity by toll-like receptors: Implications on therapeutic potential. Mediators Inflamm 2010: 865601, 2010.

118. Pevsner-Fischer M, Morad V, Cohen-Sfady M, Rousso-Noori L, Zanin-Zhorov A, Cohen S, Cohen IR and Zipori D: Toll-like receptors and their ligands control mesenchymal stem cell functions. Blood 109: 1422-1432, 2007.

119. Poulain-Godefroy O, Le Bacquer O, Plancq P, Lecoeur C, Pattou F, Frühbeck G and Froguel P: Inflammatory role of Toll-like receptors in human and murine adipose tissue. Mediators Inflamm 2010: 823486, 2010.

120. S Purohit J, Hu P, Burke SJ, Collier JJ, Chen J and Zhao L: The effects of NOD activation on adipocyte differentiation. Obesity (Silver Spring) 21: 737-747, 2013.

121. Chang LY, Lai YL, Yu TH, Chen YT and Hung SL: Effects of areca nut extract on lipopolysaccharides-enhanced adhesion and migration of human mononuclear leukocytes. J Periodontol 85: 859-867, 2014

122. Tang Y, Zhou X, Gao B, Xu X, Sun J, Cheng L, Zhou X and Zheng L: Modulation of WNT/ $\beta$-catenin signaling attenuates periapical bone lesions. J Dent Res 93: 175-182, 2014

123. Wang J, Dai J, Liu B, Gu S, Cheng L and Liang J: Porphyromonas gingivalis lipopolysaccharide activates canonical WNT/ $\beta$-catenin and p38 MAPK signalling in stem cells from the apical papilla. Inflammation 36: 1393-1402, 2013.

124. Li D, Fu L, Zhang Y, Yu Q, Ma F, Wang Z, Luo Z, Zhou Z, Cooper PR and He W: The effects of LPS on adhesion and migration of human dental pulp stem cells in vitro. J Dent 42: 1327-1334, 2014.

125. He W, Wang Z, Zhou Z, Zhang Y, Zhu Q, Wei K, Lin Y, Cooper PR, Smith AJ and Yu Q: Lipopolysaccharide enhances WNT5a expression through toll-like receptor 4, myeloid differentiating factor 88, phosphatidylinositol 3-OH kinase/Akt and nuclear factor kappa B pathways in human dental pulp stem cells. J Endod 40: 69-75, 2014

126. He W, Qu T, Yu Q, Wang Z, Wang H, Zhang J and Smith AJ: Lipopolysaccharide enhances decorin expression through the Toll-like receptor 4 , myeloid differentiating factor 88 , nuclear factor-kappa B, and mitogen-activated protein kinase pathways in odontoblast cells. J Endod 38: 464-469, 2012

127. Xing Q, Ye Q, Fan M, Zhou Y, Xu Q and Sandham A: Porphyromonas gingivalis lipopolysaccharide inhibits the osteoblastic differentiation of preosteoblasts by activating Notch1 signaling. J Cell Physiol 225: 106-114, 2010.

128. Wlodarska M, Kostic AD and Xavier RJ: An integrative view of microbiome-host interactions in inflammatory bowel diseases. Cell Host Microbe 17: 577-591, 2015.

129. Kedia S, Rampal R, Paul J and Ahuja V: Gut microbiome diversity in acute infective and chronic inflammatory gastrointestinal diseases in North India. J Gastroenterol 51: 660-671, 2016

130. Sodhi CP, Shi XH, Richardson WM, Grant ZS, Shapiro RA Prindle T Jr, Branca M, Russo A, Gribar SC, Ma C and Hackam DJ: Toll-like receptor-4 inhibits enterocyte proliferation via impaired beta-catenin signaling in necrotizing enterocolitis. Gastroenterology 138: 185-196, 2010.

131. Liu X, Lu R, Xia Y, Wu S and Sun J: Eukaryotic signaling pathways targeted by Salmonella effector protein AvrA in intestinal infection in vivo. BMC Microbiol 10: 326, 2010.

132. Suh HN, Kim MJ, Jung YS, Lien EM, Jun S and Park JI: Quiescence Exit of Tert+ stem cells by WNT/ $\beta$-catenin is indispensable for intestinal regeneration. Cell Rep 21: 2571-2584, 2017.

133. Marchetti B and Pluchino S: WNT your brain be inflamed? Yes, it WNT! Trends Mol Med 19: 144-156, 2013.

134. Jin J, Yu Q, Han C, Hu X, Xu S, Wang Q, Wang J, Li N and Cao X: LRRFIP2 negatively regulates NLRP3 inflammasome activation in macrophages by promoting Flightless-I-mediated caspase-1 inhibition. Nat Commun 4: 2075, 2013.

135. Zolezzi JM and Inestrosa NC: WNT/TLR dialog in neuroinflammation, relevance in Alzheimer's disease. Front Immunol 8: $187,2017$.
136. Kanneganti TD, Lamkanfi $\mathrm{M}$ and Núñez G: Intracellular NOD-like receptors in host defense and disease. Immunity 27 : 549-559, 2007

137. Inohara $C$, Chamaillard, McDonald $C$ and Nuñez G: NOD-LRR proteins: Role in host-microbial interactions and inflammatory disease. Annu Rev Biochem 74: 355-383, 2005.

138. Franchi L, Warner N, Viani K and Nuñez G: Function of Nod-like receptors in microbial recognition and host defense. Immunol Rev 227: 106-128, 2009.

139. Shaw MH, Reimer T, Kim YG and Nuñez G: NOD-like receptors (NLRs): Bona fide intracellular microbial sensors. Curr Opin Immunol 20: 377-382, 2008.

140. Jorgensen I and Miao EA: Pyroptotic cell death defends against intracellular pathogens. Immunol Rev 265: 130-142, 2015.

141. Franchi L, Muñoz-Planillo R and Núñez G: Sensing and reacting to microbes through the inflammasomes. Nat Immunol 13: 325-332, 2012

142. Galluzzi L, Vitale I, Aaronson SA, Abrams JM, Adam D, Agostinis P, Alnemri ES, Altucci L, Amelio I, Andrews DW, et al: Molecular mechanisms of cell death: Recommendations of the nomenclature committee on cell death 2018. Cell Death Differ 25: 486-541, 2018.

143. Naji A, Muzembo BA, Yagyu K, Baba N, Deschaseaux F, Sensebé L and Suganuma N: Endocytosis of indium-tin-oxide nanoparticles by macrophages provokes pyroptosis requiring NLRP3-ASC-Caspase1 axis that can be prevented by mesenchymal stem cells. Sci Rep 6: 26162, 2016.

144. Kim HS, Shin TH, Yang SR, Seo MS, Kim DJ, Kang SK, Park JH and Kang KS: Implication of NOD1 and NOD2 for the differentiation of multipotent mesenchymal stem cells derived from human umbilical cord blood. PLoS One 5: e15369, 2010.

145. Wang L, Chen K, Wan X, Wang F, Guo Z and Mo Z: NLRP3 inflammasome activation in mesenchymal stem cells inhibits osteogenic differentiation and enhances adipogenic differentiation. Biochem Biophys Res Commun 484: 871-877, 2017.

146. Wu XM, Chen WQ, Hu YW, Cao L, Nie P and Chang MX: RIP2 Is a critical regulator for NLRs signaling and MHC antigen presentation but not for MAPK and PI3K/Akt pathways. Front Immunol 9: 726, 2018.

147. Bist P, Dikshit N, Koh TH, Mortellaro A, Tan TT and Sukumaran B: The Nod1, Nod2, and Rip2 axis contributes to host immune defense against intracellular Acinetobacter baumannii infection. Infect Immun 82: 1112-1122, 2014.

148. Souza JA, Medeiros MC, Rocha FR, de Aquino SG, Ávila-Campos MJ, Spolidorio LC, Zamboni DS, Graves DT and Rossa C: Role of NOD2 and RIP2 in host-microbe interactions with Gram-negative bacteria: Insights from the periodontal disease model. Innate Immun 22: 598-611, 2016.

149. Singh V, Holla S, Ramachandra SG and Balaji KN: WNT-inflammasome signaling mediates NOD2-induced development of acute arthritis in mice. J Immunol 194: 3351-3360, 2015.

150. Prakhar P, Holla S, Ghorpade DS, Gilleron M, Puzo G, Udupa V and Balaji KN: Ac2PIM-responsive miR-150 and miR-143 target receptor-interacting protein kinase 2 and transforming growth factor beta-activated kinase 1 to suppress NOD2-induced immunomodulators. J Biol Chem 290: 26576-26586, 2015.

151. McGonagle D, Savic S and McDermott MF: The NLR network and the immunological disease continuum of adaptive and innate immune-mediated inflammation against self. Semin Immunopathol 29: 303-313, 2007.

152. Zhou L, Dörfer CE, Chen L and Fawzy El-Sayed KM: Porphyromonas gingivalis lipopolysaccharides affect gingival stem/progenitor cells attributes through $\mathrm{NF}-\kappa \mathrm{B}$, but not WNT/ $\beta$-catenin, pathway. J Clin Periodontol 44: 1112-1122, 2017.

153. Chen S, Shen D, Popp NA, Ogilvy AJ, Tuo J, Abu-Asab M, Xie T and Chan CC: Responses of multipotent retinal stem cells to IL-1 $\beta$, IL-18, or IL-17. J Ophthalmol 2015: 369312, 2015.

154. Huang J and Chen L: IL-1 $\beta$ inhibits osteogenesis of human bone marrow-derived mesenchymal stem cells by activating FoxD3/microRNA-496 to repress WNT signaling. Genesis: 55 , 2017 doi: 10.1002/dvg.23040.

155. Gao Y, Grassi F, Ryan MR, Terauchi M, Page K, Yang X, Weitzmann MN and Pacifici R: IFN-gamma stimulates osteoclast formation and bone loss in vivo via antigen-driven $\mathrm{T}$ cell activation. J Clin Invest 117: 122-132, 2007.

156. Suzawa M, Takada I, Yanagisawa J, Ohtake F, Ogawa S, Yamauchi T, Kadowaki T, Takeuchi Y, Shibuya H, Gotoh Y, et al: Cytokines suppress adipogenesis and PPAR-gamma function through the TAK1/TAB1/NIK cascade. Nat Cell Biol 5: 224-230, 2003. 
157. Gaspersic R, Stiblar-Martincic D, Osredkar J and Skaleric U: In vivo administration of recombinant TNF-alpha promotes bone resorption in mice. J Periodontal Res 38: 446-448, 2003.

158. Wang L, Zhao Y and Shi S: Interplay between mesenchymal stem cells and lymphocytes: Implications for immunotherapy and tissue regeneration. J Dent Res 91: 1003-1010, 2012.

159. Yang SR, Park JR and Kang KS: Reactive oxygen species in mesenchymal stem cell aging: Implication to lung diseases. Oxid Med Cell Longev 2015: 486263, 2015.

160. Kawai T and Akira S: Toll-like receptors and their crosstalk with other innate receptors in infection and immunity. Immunity 34 637-650, 2011.

161. Atashi F, Modarressi A and Pepper MS: The role of reactive oxygen species in mesenchymal stem cell adipogenic and osteogenic differentiation: A review. Stem Cells Dev 24: 1150-1163, 2015.

162. Brown GC and Borutaite V: There is no evidence that mitochondria are the main source of reactive oxygen species in mammalian cells. Mitochondrion 12: 1-4, 2012.

163. McNally JS, Davis ME, Giddens DP, Saha A, Hwang J, Dikalov S, Jo H and Harrison DG: Role of xanthine oxidoreductase and NAD (P)H oxidase in endothelial superoxide production in response to oscillatory shear stress. Am J Physiol Heart Circ Physiol 285: H2290-H2297, 2003.

164. O'Donnell VB and Azzi A: High rates of extracellular superoxide generation by cultured human fibroblasts: Involvement of a lipid-metabolizing enzyme. Biochem J 318: 805-812, 1996.

165. Starkov AA: The role of mitochondria in reactive oxygen species metabolism and signaling. Ann N Y Acad Sci 1147: 37-52, 2008

166. Gross E, Sevier CS, Heldman N, Vitu E, Bentzur M, Kaiser CA, Thorpe $\mathrm{C}$ and Fass D: Generating disulfides enzymatically: Reaction products and electron acceptors of the endoplasmic reticulum thiol oxidase Erolp. Proc Natl Acad Sci USA 103: 299-304, 2006

167. Roy P, Roy SK, Mitra A and Kulkarni AP: Superoxide generation by lipoxygenase in the presence of NADH and NADPH. Biochim Biophys Acta 1214: 171-179, 1994.

168. Schröder K, Wandzioch K, Helmcke I and Brandes RP: Nox4 acts as a switch between differentiation and proliferation in preadipocytes. Arterioscler Thromb Vasc Biol 29: 239-245, 2009.

169. Pittenger MF and Martin BJ: Mesenchymal stem cells and their potential as cardiac therapeutics. Circ Res 95: 9-20, 2004.

170. Liu SP, Ding DC, Wang HJ, Su CY, Lin SZ, Li H and Shyu WC: Nonsenescent Hsp27-upregulated MSCs implantation promotes neuroplasticity in stroke model. Cell Transplant 19: 1261-1279, 2010.

171. Kobayashi CI and Suda T: Regulation of reactive oxygen species in stem cells and cancer stem cells. J Cell Physiol 227: 421-430, 2012.

172. D'Autréaux B and Toledano MB: ROS as signalling molecules: Mechanisms that generate specificity in ROS homeostasis. Nat Rev Mol Cell Biol 8: 813-824, 2007.
173. Eto H, Kato H, Suga H, Aoi N, Doi K, Kuno S and Yoshimura K The fate of adipocytes after nonvascularized fat grafting: Evidence of early death and replacement of adipocytes. Plast Reconstr Surg 129: 1081-1092, 2012.

174. Rodrigues M, Turner O, Stolz D, Griffith LG and Wells A Production of reactive oxygen species by multipotent stromal cells/mesenchymal stem cells upon exposure to fas ligand. Cell Transplant 21: 2171-2187, 2012.

175. Zou X, Li H, Chen L, Baatrup A, Bünger C and Lind M: Stimulation of porcine bone marrow stromal cells by hyaluronan, dexamethasone and rhBMP-2. Biomaterials 25: 5375-5385, 2004.

176. Denu RA and Hematti P: Effects of oxidative stress on mesenchymal stem cell biology. Oxid Med Cell Longev 2016: 2989076 2016.

177. Valle-Prieto A and Conget PA: Human mesenchymal stem cells efficiently manage oxidative stress. Stem Cells Dev 19 $1885-1893,2010$

178. Orciani M, Gorbi S, Benedetti M, Di Benedetto G, Mattioli-Belmonte M, Regoli F and Di Primio R: Oxidative stress defense in human-skin-derived mesenchymal stem cells versus human keratinocytes: Different mechanisms of protection and cell selection. Free Radic Biol Med 49: 830-838, 2010.

179. KoE,Lee KY andHwang DS:Human umbilical cordblood-derived mesenchymal stem cells undergo cellular senescence in response to oxidative stress. Stem Cells Dev 21: 1877-1886, 2012.

180. Hou J, Han ZP, Jing YY, Yang X, Zhang SS, Sun K, Hao C, Meng Y, Yu FH, Liu XQ, et al: Autophagy prevents irradiation injury and maintains stemness through decreasing ROS generation in mesenchymal stem cells. Cell Death Dis 4: e844, 2013.

181. Kanda Y, Hinata T, Kang SW and Watanabe Y: Reactive oxygen species mediate adipocyte differentiation in mesenchymal stem cells. Life Sci 89: 250-258, 2011

182. Zhang Y, Marsboom G, Toth PT and Rehman J: Mitochondrial respiration regulates adipogenic differentiation of human mesenchymal stem cells. PLoS One 8: e77077, 2013.

183. Ren J, Stroncek DF, Zhao Y, Jin P, Castiello L, Civini S, Wang H, Feng J, Tran K, Kuznetsov SA, et al: Intra-subject variability in human bone marrow stromal cell (BMSC) replicative senescence: Molecular changes associated with BMSC senescence. Stem Cell Res (Amst) 11: 1060-1073, 2013.

184. Sallman DA, Cluzeau T, Basiorka AA and List A: Unraveling the pathogenesis of MDS: The NLRP3 inflammasome and pyroptosis drive the mds phenotype. Front Oncol 6: 151, 2016.

185. Kajla S, Mondol AS, Nagasawa A, Zhang Y, Kato M, Matsuno K, Yabe-Nishimura C and Kamata T: A crucial role for Nox 1 in redox-dependent regulation of WNT- $\beta$-catenin signaling. FASEB J 26: 2049-2059, 2012 